Acero, C. (2016). Crisis cafetera, conflicto armado y cultivos ilícitos en el oriente caldense: el caso de Samaná. Revista de Sociología y Antropología: VIRAJES, 18 (1), 47-85. DOI: 10.17151/rasv.2016.18.1.4

\title{
CRISIS CAFETERA, CONFLICTO ARMADO Y CULTIVOS ILÍCITOS EN EL ORIENTE CALDENSE: EL CASO DE SAMANÁ*
}

\section{CAMILO ACERO**}

Recibido: 14 de septiembre de 2015

Aprobado: 29 de octubre de 2015

Artículo de Investigación

\footnotetext{
* El presente artículo surge de un proyecto de investigación exploratoria que se construyó en el marco de la asignatura "Tierra y conflicto" orientada por el profesor Francisco Gutiérrez, la cual hace parte de la maestría en Estudios Políticos de la Universidad Nacional de Colombia.

** Politólogo Universidad Nacional de Colombia -Sede Bogotá, Estudiante de la Maestría en Estudios Políticos del IEPRI -Universidad Nacional de Colombia. Correo electrónico: caacerov@unal.edu.co. (1) ORCID: 0000-0003-2841-3651
} 


\title{
Resumen
}

El artículo expone de manera detallada el conjunto de condicionamientos económicos, políticos y sociales que explican el proceso de sustitución de cultivos de café por cultivos de coca en el municipio caldense de Samaná a finales del siglo pasado. En éste, se explica la relación entre los distintos fenómenos que llevaron a esa reconversión productiva, a saber: la relegación temprana de la localidad del modelo productivo cafetero, el impacto de la crisis del sector agroexportador, la presencia precaria del Estado en la región, la configuración del territorio como zona de conflicto armado y la socialización de los campesinos de Samaná en el mundo de los cultivos ilícitos. Finalmente, se revisan las trágicas consecuencias que trajeron la guerra y la coca para los pobladores del oriente caldense.

Palabras clave: conflicto armado, crisis cafetera, cultivos ilícitos, presencia diferenciada del Estado, Eje Cafetero.

\section{COFFEE CRISIS, ARMED CONFLICT AND COCA CROPS IN EASTERN CALDAS: THE CASE OF SAMANÁ}

\begin{abstract}
This document presents the set of economic, political and social conditions that explain the process of replacement the coffee crops by coca crops in the municipality of Samaná, in the department of Caldas at the end of the last century. It explains the relation between the different kind of phenomena that caused this productive transformation: the relegation of the municipality in the economic development associated with production and trade of coffee, the impact of the crisis in the agroexportation sector, the weak presence of State in the region, the armed conflict and the socialization of Samana's peasants in the world of ilegal crops. Finally, it examines the aftermath of war and coca in western Caldas.
\end{abstract}

Key words: armed conflict, coffee crisis, ilegal crops, state presence, Eje Cafetero. 


\section{1- Introducción}

$\mathrm{P}$ ara finales de la década de los años ochenta y principios de los noventa, se evidenció la crisis por la que atravesaba el modelo productivo del café agenciado por la Federación Nacional de Cafeteros (FNC) durante más de medio siglo. A los problemas estructurales se les sumaron las dificultades ambientales y la ruptura del Pacto Internacional del Café en 1989, con la consecuente caída del sistema de cuotas que hasta la fecha mantenía estables los precios del grano. La crisis, que se extendió por los diferentes municipios caficultores, tuvo un fuerte impacto en la región con la mayor producción del país: el Eje Cafetero $(\mathrm{EC})^{1}$.

En esta región, que comprende los departamentos de Caldas, Risaralda y Quindío, había existido una presencia marginal de los grupos armados hasta la década de 1990. Según información del Observatorio del Programa Presidencial de DDHH y DIH, la presencia de organizaciones armadas ilegales que en 1985 se registraba en un 2\% de los municipios cafeteros, para 1995 se extendía al 53\% de ellos (Vicepresidencia, 2001). Así, en unos pocos años se configuró un espacio en el que convergían los narcotraficantes; los frentes 9, 47 y 50 de las Farc; algunas estructuras del ELN; y, más tarde, ciertos grupos paramilitares vinculados a las Autodefensas del Magdalena Medio. La incursión de estas organizaciones armadas en diferentes localidades cafeteras dejó como saldo un incremento sustancial en las tasas de homicidios, desplazamientos, despojo de tierras, secuestros y extorsiones.

Esta situación causó aún más alarma cuando las directivas cafeteras, los representantes del gobierno y algunas organizaciones internacionales anunciaron escandalizados que los campesinos de la región estaban reemplazando el café por la coca. La explicación de este fenómeno que acaparó el debate público se basó en el argumento de que el deterioro de los ingresos del caficultor y los diferenciales en los salarios por la actividad ilícita, junto con la presencia de los grupos irregulares, favorecieron la implantación de los cultivos proscritos ${ }^{2}$. Con ese razonamiento las cabezas de la FNC descargaban la responsabilidad en las fuerzas del mercado internacional, que hicieron bajar el precio del grano, y en el gobierno, quien, según ellos, se mostraba incapaz de controlar el orden público en

\footnotetext{
${ }^{1}$ Para el año 2002, los departamentos de la región centro-occidente (Antioquia, Caldas, Quindío, Risaralda, Tolima y Valle) contribuían con el $65.9 \%$ al total de la oferta nacional (CRECE, 2002).

${ }^{2}$ Esta fue la explicación que dieron los directivos de la FNC a la Defensoría del Pueblo, y que esta cita en la resolución defensorial número 28 de 2003: "La crisis cafetera y las fumigaciones en el departamento de Caldas".
} 
la zona. Por su parte, los voceros del gobierno se despachaban en contra de los grupos armados ilegales que, de acuerdo con su entender, estaban transformando la figura emblemática de Juan Valdez, el cafetero, en la de un coquero.

Estos hechos no despertaron mucho interés en su momento ni para los estudiosos del conflicto armado -en términos comparativos la región no fue tan golpeada por el escalamiento de la guerra como otras ${ }^{3}$ - ni para los estudiosos de la economía- el café ya no era tan significativo para el conjunto de la economía nacional como lo fue hasta los setenta ${ }^{4}$. Sin embargo, instituciones encargadas del seguimiento a los DDHH, agencias internacionales y las mismas entidades vinculadas a la FNC sí se mostraban extrañadas por la forma tan fácil como los grupos ilegales se habían apoderado de ciertas zonas de una región que se creía "blindada" por su nivel elevado de prosperidad y desarrollo.

Los pocos investigadores y entidades oficiales que se preocuparon por comprender la dinámica del conflicto armado en el EC compartían la idea de que las guerrillas habían llegado a la región, no tanto por el deterioro de las condiciones de vida de la población rural a raíz de la crisis cafetera, sino como parte de sus planes estratégicos de expandirse para cercar las capitales e impulsar los cultivos de coca. Además, señalaban que los paramilitares de otros lugares se desplazaron hacia la región cafetera con el propósito de confrontar a los subversivos recién instalados (Echandía, 1998; Cubides, 1998; Vicepresidencia, 2001 y 2005).

No obstante, en los años posteriores aparecieron algunos textos académicos que proponían una explicación diferente. Desde una lectura económica del conflicto, Dube y Vargas (2006) planteaban que la caída en el precio del grano incrementó la incidencia y la intensidad del conflicto armado en los municipios caficultores ${ }^{5}$. Los autores identificaron dos mecanismos relevantes ${ }^{6}$. De un lado, con la reducción del precio del café se redujo también la demanda de trabajo en la economía cafetera y, por tanto,

\footnotetext{
${ }^{3}$ El escalamiento del conflicto en Caldas a finales del siglo pasado e inicios de este no tuvo las mismas proporciones que en el resto del país (Ver Gráfica 1 en Anexos).

${ }^{4}$ La economía cafetera, que llegó a aportar durante los primeros años de la segunda mitad del siglo XX entre el 50 y el $70 \%$ del PIB, para finales de la década de los años noventa aportaba el $17 \%$.

${ }^{5}$ Sobre la base de diferentes datos, identifican 581 municipios productores de café en el país para el período estudiado y afirman que, en comparación con los no cafeteros, estos registraron mayores niveles de pobreza, menores niveles de inversión pública y una mayor intensidad e incidencia del conflicto durante los años de la caída de precios del grano. Estos resultados los interpretan diciendo que si no se hubieran dado los cambios en el precio del café, los niveles de violencia no hubieran variado entre las áreas productoras y las no productoras, sino que ambas hubieran seguido la tendencia del período (Dube y Vargas, 2006, p. 16).

${ }^{6}$ Sorprendentemente, los autores afirman que con la crisis no se produjo una sustitución de cultivos en municipios cafeteros en una mayor proporción que los no cafeteros, por lo que este mecanismo no es tan relevante.
} 
los salarios esperados de los potenciales cultivadores, lo que hizo más atractivas alternativas como el apoyo a los grupos ilegales (Dube y Vargas, 2006, p. 27). En pocas palabras, los grupos irregulares se convirtieron en los empleadores de la región. Por otra parte, la crisis deterioró la institucionalidad en estos municipios lo que los hizo más vulnerables al conflicto, ya que con la caída de los precios del café, las administraciones locales redujeron sus inversiones y los grupos ilegales aprovecharon entonces para atacar las zonas con un Estado más debilitado (Dube y Vargas, 2006, p. 29).

Otro trabajo fue el de Franco (2006), para quien el capital social en el EC se vio alterado con la crisis presupuestal de la FNC y de los diferentes órganos encargados de regularla economía cafetera en lo local y departamental. Esto derivó en una intensificación de la confrontación armada en aquellas regiones del EC con menor presencia de la federación, dado que "para el agente generador de violencia, en la medida en que la presencia estatal sea menor, el poder de disuasión de la cohesión social generada en la comunidad será más bajo y su estrategia de debilitar el tejido social tendrá un mayor efecto positivo para él y un mayor perjuicio para la comunidad" (Franco, 2006, p. 40).

Con esta breve mención de las explicaciones disponibles buscaba presentar al lector el panorama general del objeto del que me ocuparé en este artículo. Mi propósito es aportar, a partir del estudio de caso de un municipio caldense (Samaná), algunos elementos que ayuden a resolver la pregunta de por qué y cómo emergió la economía de la coca en la principal región cafetera a finales de la década de los años noventa. Esa pregunta lleva, a su vez, a indagar por la relación de la economía y la institucionalidad del café con esos fenómenos.

En ese sentido, en este artículo se explorará un proceso concreto y complejo en el que se dio una imbricación de las condiciones objetivas (económicas y políticas) de la localidad, definidas por el desarrollo particular del modelo productivo cafetero; las disposiciones subjetivas de sus habitantes, signadas por su socialización en el cultivo de las plantas proscritas en otras regiones del país; y la dinámica propia de la guerra. Tal confluencia de factores hizo posible la sustitución de los cultivos de café por coca.

Resta explicitar las razones para la escogencia del municipio caldense de Samaná. La literatura sobre el conflicto ha concentrado su atención en determinadas regiones del país que por diversos motivos resultan significativas para los analistas. En particular, con respecto a la economía cocalera y sus vínculos con el conflicto armado, se han privilegiado regiones periféricas de frontera agrícola, donde los impactos de ambos fenómenos 
han sido más evidentes; mientras que regiones que se consideran integradas al mercado y a la política nacional -como el EC- han sido poco tomadas en cuenta. La razón de este poco interés quizás tiene que ver con el hecho de que, comparativamente, la magnitud de los dos procesos en la zona cafetera fue mucho menor. Sin embargo, es justamente por las características particulares del EC que lo diferenciaban radicalmente de las zonas periféricas y de frontera ${ }^{8}$, que adquiere importancia la pregunta sobre la implantación de la economía ligada a las drogas ilícitas en uno de sus municipios. En este caso, Samaná presenta las condiciones de ser un municipio cafetero en el cual se dio un proceso de sustitución de cultivos por coca a finales de los años noventa y sobre el cual recayó el infortunio de ser una de las localidades más golpeadas por el conflicto en toda la región?.

En términos metodológicos, la información recolectada para elaborar el artículo proviene de la revisión de la bibliografía relevante acerca de la economía del café en Caldas y en Samaná, de la exploración de informes oficiales y no oficiales sobre el conflicto armado en la región y del examen a la prensa local y nacional. Adicionalmente, se realizó trabajo de campo en el casco urbano y en el sector rural de la localidad con el propósito de recolectar los testimonios de caficultores y funcionarios de entidades públicas.

El texto se divide en tres partes. En la primera se describe el proceso de marginación productiva del municipio y sus consecuencias en términos de su desarrollo económico y social rezagado frente a otras regiones cafeteras, y los impactos diferenciados de la crisis cafetera en esta región relegada. En el segundo apartado, se examinan la incapacidad de la institucionalidad estatal para controlar el territorio y la población de la localidad; la consecuente inserción de los grupos armados, especialmente la guerrilla, y la configuración por esa vía de una zona de conflicto armado; y el proceso propiamente dicho de la reconversión productiva del café por la coca. Por último, se incluyen las conclusiones de la investigación.

\footnotetext{
7 Particularmente en zonas como Cauca, Putumayo, Caquetá y Norte de Santander.

${ }^{8}$ Se asumía que el EC, dado el impulso de la economía cafetera, era una región con altos niveles de desarrollo económico vía integración al mercado nacional e internacional y con una presencia institucional fuerte garantizada por la FNC, rasgos ausentes en las regiones de frontera agrícola.

${ }^{9}$ De acuerdo con la base de datos del CERAC, sólo cuatro municipios de los tres departamentos que integran la región del EC presentan un grado de conflicto (medido a partir del promedio de eventos del conflicto armado respecto a la media nacional) considerado de alta intensidad entre 2000 y 2012, entre ellos se encuentra Samaná. Fuente: https://docs.google.com/spreadsheets/d/1ITvbEU79Ok_ GhaDmN12mCeHBFfBzoa4GfNT68wyAnXo/edit\#gid=1514359174
} 


\section{2- La marginación de Samaná como resultado del desarrollo desigual en Caldas}

Para finales del siglo XIX, el Antiguo Caldas ${ }^{10}$ participaba con el 1\% en la producción de café, en 1930 ya representaba el 25\% de la producción nacional. Así mismo, su aporte a las exportaciones del grano alcanzó el 12\% hasta mediados del siglo pasado y llegó a contener el $24 \%$ del área destinada a la caficultura en el país, por encima del resto de regiones cultivadoras (Vallecilla, 2002). Este desarrollo de la economía cafetera le permitió gozar a la región, entre otras cosas, de unos niveles altos de ingresos per cápita, de prestación de servicios públicos y de infraestructura; tanto así que se empezó a hablar de la "civilización cafetera", un epíteto un tanto estrafalario para referirse al departamento que promediando la centuria anterior, disfrutaba del nivel de vida más alto en Colombia (Currie, 1952).

Pero así como el país asistió al surgimiento de un área agrícola y comercial próspera en los años treinta, para finales de siglo veía cómo la "civilización" levantada sobre el cafetal se tambaleaba. Sumado a los efectos socioeconómicos de la crisis, el terremoto de 1999 y la llegada de los grupos armados ilegales terminaban por oscurecer aún más el paisaje. No obstante, como afirman varios estudiosos del fenómeno, tanto la crisis cafetera como las soluciones que se le dieron a ella dejaron en evidencia las serias dificultades inherentes a un modelo productivo que mientras salvaba a unas regiones, empujaba a otras al olvido (Rincón, 2006). En las páginas que siguen se abordará de forma muy resumida el proceso de desarrollo de la economía cafetera en Caldas y el modo en que produjo la marginación de ciertos territorios como el oriente caldense, en particular la localidad de Samaná. Luego de esto se describirán los efectos de la crisis y la forma en que agudizó la ya difícil situación del municipio y de sus habitantes. Este apartado presentará entonces las condiciones económicas que sirven de base para que emerja la economía de la coca.

\section{Breves apuntes sobre la economía cafetera en Caldas}

Durante el siglo XIX, la producción del café se concentraba principalmente en el oriente colombiano. Departamentos como Boyacá, Cundinamarca, Santander y Magdalena poseían grandes haciendas cuyas extensas zonas de cultivo dedicadas al grano hacían que produjeran en promedio 195.000 sacos anualmente (Arango, 1977). Pero hacia finales de

\footnotetext{
${ }^{10}$ Este departamento comprendía los tres departamentos que integran la región del EC hasta que en 1968 se dividió, dando lugar al surgimiento de Risaralda y Quindío.
} 
ese siglo, la producción se había expandido rápidamente al occidente del país (Antioquia, Caldas, Cauca y Tolima), e iniciando la nueva centuria ya esta zona se había convertido en un centro importante de producción cafetera que llegaba a participar con una cuarta parte de la producción del país (Vallecilla, 2002, p. 139).

En Caldas, el establecimiento de los primeros cafetales registrados, o al menos los más importantes, fueron realizados por empresarios que tuvieron dentro de sus actividades económicas la apertura de tierras, el comercio, la construcción de caminos, la minería y la introducción de maquinaria agrícola (Machado, 1978) (Vallecilla, 2002). Estos personajes encuentran en el alza de precios del café de importación en 1870 y en las mejorías de la red de transportes una oportunidad para reinvertir el capital acumulado en tales actividades en el sector agroexportador.

Pero no fueron sólo las acciones de los más adinerados las que explican la expansión geográfica del cultivo del café en este departamento, este proceso tuvo que ver, como lo referencian Palacios (1983) y Machado (1978), con la adaptación de las formas de producción familiar implementadas por los colonos a las exigencias de la agricultura para el mercado externo. La agricultura familiar se constituyó como una unidad de explotación completa en la que el productor no sólo cultivaba café para los mercados, sino que también sembraba productos de pancoger para responder a la demanda familiar, lo que generaba un equilibrio mantenido con la generación de ingresos monetarios que ampliaba los niveles de satisfacción de los productores.

Así, para el pequeño campesino "la capacidad de producir permanentemente un excedente, la rentabilidad en pequeñas parcelas, la coexistencia de los cultivos de subsistencia con el café, las características del suelo, el clima, los bajos requerimientos de capital para iniciar una explotación en zonas donde este factor no era el más abundante y las escasas alternativas de inversión, fueron factores que [le] facilitaron el acceso al cultivo" (Machado, 1978, p. 34). Esto dio como resultado una forma de participación de las economías familiares en el proceso productivo cafetero que permitía un acceso relativamente generalizado y estable a ingresos por parte de los productores. No obstante, por las mismas características de la economía cafetera, la acumulación de capital no se dio de forma homogénea entre los distintos actores y entre las diferentes regiones del departamento.

Como es sabido, son tres las actividades que constituyen esta economía: la caficultura, el beneficio ${ }^{11}$ y la exportación. La primera se caracterizó por la presencia de un gran número de unidades de explotación

\footnotetext{
${ }^{11}$ El beneficio del café se extiende a la despulpada, lavada, secada y trillada del grano.
} 
agrícola producto de la ya mencionada adaptación de la producción familiar al cultivo del grano, mientras que en las actividades de beneficio y exportación no hubo atomización en cuanto que eran pocas las empresas organizadas con la capacidad de desarrollar estas labores. En la práctica, la producción agrícola se diseminó en los diferentes municipios de la región y la labor de procesamiento y exportación del grano se concentró en Manizales, Pereira y Armenia. Así mismo, las mayores utilidades las reportaron los sectores que monopolizaron las actividades de beneficio y exportación y no los productores.

El momento productivo del beneficio demanda de inversión de capital fijo como trilladoras, hornos y planchas de lavado, así como de la ejecución de trabajo especializado ${ }^{12}$. Es fundamentalmente una actividad semi-industrial, en tanto ejerce sobre el grano un proceso de transformación y procesamiento en virtud de su comercialización. Su importancia se manifiesta en la disminución de los costos de producción que trae principalmente por concepto de rendimiento y mejoramiento de la calidad, lo que le da una mejor posición en el mercado (Vallecilla, 2002). Por lo anterior, la capacidad técnica y racionalizada del cultivo y el beneficio eran factores determinantes en la productividad y calidad del café, lo que se tradujo tempranamente en procesos de acumulación de capital diferenciales entre las zonas donde se concentró la trilla y el comercio, y aquellas de predominancia del minifundio familiar. En estas últimas, la fragmentación geográfica de la producción llevó al embotellamiento de las economías familiares dado que implicaba para los productores mayores costos por secado artificial, un aumento de gastos de transporte a trilladoras y la posibilidad de fermentación del grano (García, 1978, p. 28).

Esa centralización del beneficio en trilla en fincas comerciales de las ciudades se explica, primero, por el proceso de acumulación previo por parte de los hombres de negocios que, como se dijo arriba, estuvieron asociados con otras actividades antes de ingresar a la economía del café ${ }^{13}$. Al contar con un volumen considerable de capital económico, los hombres

\footnotetext{
${ }^{12}$ Para 1925 había en Caldas alrededor de 9.098 despulpadoras y cerca de 55 trilladoras, operadas por obreros calificados, braceros, asalariados, escogedoras asalariadas en diferentes tipos de bandas y escogedoras por tareas [...] existía para 1936 un personal aproximado de 2.412 escogedoras de café, de las cuales el $60 \%$ correspondía al grupo de trilladoras tecnificadas de Armenia, Pereira y Manizales (García, 1978, pp. 305-308).

${ }^{13}$ Es el caso del empresario Carlos E. Pinzón Posada. Heredero de la hacienda El Águila, importante inversionista en fincas cafeteras en el valle del río Risaralda y en las cercanías de Manizales. La comercialización del café, puesto que era dueño de 26 agencias de compras, le permitió el montaje de trillas en Caldas, cerca de 20 en la región. Igualmente, era propietario de ocho barcos para exportar café vía al Pacífico, pero también por el cable aéreo vía al Magdalena. Su papel de exportador de café, le llevó a invertir capital en bancos como los de Caldas y Andes, así como establecer importantes puentes de comercialización con tostadoras de Europa y Estados Unidos. (Rodríguez, 1993).
} 
de negocios de la región pudieron orientar sus inversiones para adquirir la maquinaria moderna que les garantizaba una mejor posición en el mercado, en contraste con los campesinos pequeños y medianos cuyas posibilidades de acumulación y, por tanto, de inversión en tecnología, eran del todo limitadas. En segunda medida, por el hecho de que los tres centros urbanos más importantes eran los principales centros de acopio y de comercialización del café, lo que garantizaba un orden de costos de producción más bajo y, por consiguiente, la concentración del beneficio de la trilla en esos lugares ${ }^{14}$ (Ver Tabla 1 en los anexos).

El avance técnico que consistió en el reemplazo de los motores que funcionaban con energía hidroeléctrica por eléctrica y que redundó en la integración de los beneficiaderos con los centros de acopio y puntos de comercialización, agudizó la condición de dualidad productiva entre las pequeñas y medianas fincas cafeteras y las fincas comerciales con beneficiaderos tecnificados. Estas últimas, mejor ubicadas en el mercado, terminaron desplazando por medio de la competencia a aquellas explotaciones de pequeños y medianos caficultores que mantuvieron los métodos tradicionales de selección, lavado y secado del grano. Las desventajas productivas que se fueron demarcando se evidenciaban intensamente en tiempos de crisis de precios, representando para muchos de ellos el desplazamiento de las unidades de beneficio, y en esa medida, apartándose de los mayores márgenes de ganancia del negocio. Fue así que con la evolución técnica del beneficio se acentuó más la relación entre la calidad del grano y su valor comercial, y se consolidó el predominio de los sectores que monopolizaban el momento del beneficio y la exportación sobre los productores.

En síntesis, el proceso de concentración en las ciudades principales de las actividades de la trilla y la exportación, que eran las que otorgaban un mayor margen de ganancia en la economía cafetera, implicó el rezago social y económico de las subregiones donde predominaban los productores pequeños y medianos que se mostraban incapaces de competir con las fincas comerciales que habían tecnificado las labores del beneficio. Ahora bien, los ingresos de los cultivadores dependían no sólo de los precios internacionales del café sino también de la calidad del grano y de los costos de transporte derivados de su posición respecto a los centros de acopio y comercialización. Los productores del oriente de Caldas (Ver Mapa 1), y en particular del municipio de Samaná, dadas estas circunstancias, no gozarían de las mejores condiciones en el mercado.

\footnotetext{
${ }^{14}$ Manizales, Armenia y Pereira llegaron a poseer para 1945 el 75\% de la capacidad instalada de la región, mientras que para el mismo año habían desaparecido, en quince municipios, la mitad de las trilladoras que existían en 1925 (Ver Tabla 2) (Vallecilla, 2002).
} 
Para empezar, la localidad de Samaná, por sus características topográficas, sufrió un proceso tardío y débil de ocupación territorial a diferencia de otras zonas de colonización antioqueña. Su quebrada topografía (Ver Mapa 2) mantuvo alejados a los grupos comerciantes que se establecieron en Manizales, lo que privó al municipio del desarrollo de las relaciones mercantiles y de la conformación del mercado interno que llegaron a tener otras subregiones aledañas al núcleo de ordenamiento territorial del siglo XIX y XX (Leguizamo, 2011). El establecimiento de familias campesinas, que se dedicaron primero a la agricultura para la subsistencia y luego al cultivo del café (bajo las condiciones anotadas atrás), sentó las bases para la implantación de la economía agroexportadora en la localidad sobre la base de pequeños y medianos productores. Pero el hecho de que Samaná sea la zona más lluviosa y húmeda del departamento por causa del fenómeno orográfico del valle del Magdalena (CORPOCALDAS, 1998, p. 23), dificultó la actividad agrícola, en especial del café. Así las cosas, con la concentración de las labores de trilla y exportación en Manizales, los caficultores del municipio quedaron peor posicionados en el mercado, en tanto que los costos de transporte eran altos por la deficiencia vial y el valor comercial de su producto era menor por la baja calidad del grano ${ }^{15}$.

El proceso de aislamiento temprano de los ejes de desarrollo regional no fue remediado con la asimilación de la producción de café en el municipio, por el contrario y atendiendo a lo expuesto antes, el modelo productivo del café reprodujo ese rezago. Un indicador de esto es el atraso de su infraestructura vial, que se manifiesta en el hecho de que promediando el siglo pasado las zonas cultivadoras "en poco se diferenciaban de los caminos de herradura de la colonización", hasta el punto que en 1953 Samaná era uno de los pocos pueblos de Caldas que no disponían de carretera (Leguizamo, 2011, p. 46). La situación no es muy distinta en la actualidad. ${ }^{16}$

El otro indicador del débil desarrollo económico del municipio producto de los factores antes mencionados es su nivel bajo de crecimiento poblacional en comparación con la zona interior de Caldas. Para mediados del siglo XX, la región circundante a Manizales concentraba en un $89 \%$ la población del departamento con un promedio de densidad poblacional de $59.5 \mathrm{hab} . / \mathrm{Km} 2$. Por su parte, regiones como el oriente en las que la dificultad topográfica dificultaba el desarrollo vial y resistía al comercio, mostraban

\footnotetext{
${ }^{15} \mathrm{~A}$ causa del régimen de lluvias y el elevado nivel de humedad.

${ }^{16}$ De acuerdo con el POT de Samaná del año 2011: "el mayor porcentaje de infraestructura pertenece a las vías no pavimentadas, cuya influencia constituye una forma de conexión rural inter veredal y urbano-veredal, las cuales son utilizadas por los campesinos para su desplazamiento personal y de productos a comercializar. Son vías regularmente malas con un marcado deterioro de la base (...) Las vías pavimentadas constituyen el menor porcentaje de infraestructura carreteable alcanzando solo el $6.15 \%$ ( $20 \mathrm{Kms}$ ) de la malla vial total, donde $18 \mathrm{Kms}$ se encuentran en buen estado y $2 \mathrm{Kms}$ para reparchar."
} 
apenas un $0.81 \%$ de la población con una densidad poblacional de 6 hab/ $\mathrm{Km}^{2}$ (Leguizamo, 2011).

La situación de Samaná, caracterizada por un desarrollo económico y social desigual con respecto a otras regiones más integradas a los circuitos comerciales del departamento, tuvo cierta mejoría con la consolidación de la Federación Nacional de Cafeteros como principal comercializadora del café. El precio de sustentación a los caficultores que se extendió en 1948 a todos los tipos de grano, las facilidades otorgadas a los productores para que vendieran sus cosechas a las cooperativas ubicadas en cada municipio y la inversión del excedente cafetero en adecuación de vías, provisión de servicios públicos y acompañamiento técnico por parte del Comité Municipal de Cafeteros fueron un ejemplo de las labores adelantadas por el gremio en la localidad. No obstante, la mejora en los ingresos de los productores reforzada por las diferentes bonanzas no implicó una distribución equitativa de las ganancias del negocio entre todos los partícipes del mismo; el capital seguía siendo acumulado en mayor proporción por aquellos que monopolizaban las labores del beneficio y la exportación en Manizales, quienes habían invertido el excedente en nuevas actividades como la industria ${ }^{17}$, mientras que los cultivadores de Samaná apenas lograban mantener un nivel de consumo de bienes básicos y algunos servicios (Ver Tabla 3), y conseguir el capital para reinvertir en los insumos necesarios para la siguiente cosecha.

Un caficultor de la localidad comenta su percepción sobre la situación de esos agricultores

El cafetero nunca ha tenido respiraciones buenas, por ahí les dan lagrimitas, pero el cafetero siempre ha sido esclavo en la caficultura. Y el cafetero tiene esto: que muere de viejo y no tiene un ahorro (...) porque no le queda. Entonces al café se le saca y hay que volverle a invertir o si no no (...) puede esperar cosecha (...) Decían unos 'el café para mí no es renta, porque lo que produce por el copo hay que volverlo a mandar por la raíz en deshierba y abonos'. Eso ha sido difícil (...) eso tiene que tener uno alma de torero pa' seguir enfrentando, porque cuando menos creyó uno (...) le da por revolcarlo; pero no, el hombre se hizo pa' enfrentar lo que sea.". (Entrevista realizada a un caficultor en Samaná en 2014)

Por eso, para finales de siglo Samaná seguía siendo uno de los municipios menos poblados, menos urbanizados y menos integrados al mercado de la capital departamental, a pesar del "alma de torero" de sus caficultores.

\footnotetext{
${ }^{17}$ Los capitales invertidos en las primeras actividades fabriles de la ciudad de Manizales no procedieron de otra fuente que no fuera el comercio y el café (Giraldo, 2001).
} 
Pero si, a pesar de la condición de marginación del modelo productivo, los pequeños y medianos productores de Samaná lograban mantener unos ingresos por los buenos precios que gozaba el café en los mercados internacionales y por las políticas de la Federación, la crisis terminaría por agudizar su rezago productivo al punto de comprometer la reproducción de su modo de vida.

\section{La crisis cafetera y su impacto diferenciado en Samaná}

Como efecto de la ruptura del pacto internacional de cuotas en 1989 -y de las abruptas fluctuaciones de los precios en el mercado mundial del café sobrevenidas después de este hecho ${ }^{18}$ de la pérdida de importancia del sector cafetero en la economía, de las enfermedades fitosanitarias de los cultivos y de las variaciones en el régimen de lluvias, en la década de 1990 se agudiza el proceso de crisis cafetera en Colombia (Rincón, 2006).

Suceden a esta crisis una serie de transformaciones promovidas por el mercado internacional que llevaron a un nuevo reajuste del modelo productivo cafetero impulsado por la FNC. Empero, los ajustes en virtud de las nuevas condiciones del mercado global se aplicaron de manera desigual y desequilibrada incluso dentro de la región cafetera. Así, en regiones periféricas al modelo como la localidad caldense de Samaná, las adecuaciones impulsadas por la federación llegaron de forma restringida o marginal, lo cual condujo al detrimento de las condiciones de vida de los caficultores de la zona.

La federación adelantó una serie de acciones con miras a atender la crisis en la caficultura colombiana; medidas que simultáneamente debían responder a la necesidad de competencia del modelo productivo en el mercado mundial del café. Por los altos costos en producción y operación del modelo, fue imperativo iniciar con una serie de ajustes en el gasto administrativo de la institución. Por eso, entre 1999 y 2002, el gasto institucional se redujo de 530 mil millones a 190.900 millones de pesos. Las consecuencias de este hecho fueron el recorte de personal de 3.800 a 452 empleados, y una disminución en las funciones de apoyo a la producción e

\footnotetext{
${ }^{18}$ Según la Comisión de Ajuste de la Institucionalidad Cafetera (2002), en 1994 tanto el precio externo como interno se situaron por debajo de US\$1/lb; de 1994 a 1999 los precios variaron notablemente mostrando dos breves alzas: una a finales de 1994 de US $\$ 2.32 / 1 b$ y otra en 1997 de US\$3.19/lb; entre 1997 y 2003, ambos precios registran un descenso muy cercano al del año 1994, alcanzando el precio interno en el 2002 una posición similar a los precios de 1821, de US\$0.60/lb. La volatilidad de los precios durante gran parte de la década de 1990, privaba de capacidad acumulativa de capital al sistema productivo cafetero, que llegó a su punto crítico entre 1997 y 2003, periodo en el que se presentó una mayor disminución de los ingresos en los caficultores, seguido por el deterioro financiero de la institucionalidad cafetera.
} 
inversión social, principalmente en regiones productoras periféricas donde las ventajas comparativas no favorecían el desarrollo de una caficultura competitiva.

[...] parte de la transición demanda el abandono de una serie de funciones de inversión social, realizadas por la Federación a lo largo de la historia en función del modelo productivo, y que ahora consideran, son competencia exclusiva del Estado. Por otro lado, empiezan a ser desmontados los programas de asistencia técnica prestada a productores ubicados en zonas marginales de producción, en virtud de que los primeros funcionarios despedidos de la entidad, fueron aquellos que tenían el contacto directo con los productores, seguidos de administradores y asesores de gerencia. (Rincón, 2006, p. 20)

El tratamiento que le dio el gremio cafetero a la situación de crisis llevó a que programas como la renovación de cafetales, la política de mantenimiento del precio interno, el apoyo financiero mediante líneas de crédito, entre otros, fueran suspendidos en su momento; entre tanto, la relación negativa entre los ingresos y los costos de producción de los caficultores quedaba sin una solución clara. La nueva política cafetera priorizó entonces la mejora en la competitividad del modelo productivo en el mercado mundial. Esta reorientación de la política significó, además de la contracción de las funciones de la institucionalidad cafetera,la focalización de las medidas de ajuste en un sector específico de la estructura productiva de la región cafetera: aquel que garantizara el éxito de la inversión de capital en términos de disminución de costos, modificación de capital y prácticas competentes de producción. ${ }^{19}$

Bajo esta lógica, la federación dispuso un paquete de bienes públicos productivos al conjunto de productores que enviaran señales de competitividad. Como era de esperarse de una política que partía del supuesto de que eran los mismos caficultores quienes por sus propios medios debían ajustarse a la nueva dinámica del mercado, se terminó por favorecer a los productores que históricamente habían estado en mejor posición. Estos fueron, mayoritariamente, los grandes productores, pues eran los que poseían mayor capacidad de acumulación y mejores condiciones productivas, y por ende, los que mejor se ajustaban a los criterios

\footnotetext{
${ }^{19}$ Según la Comisión de Ajuste de la Institucionalidad Cafetera (2002), las variables para hacer a la caficultura más competente eran: el sistema de producción; la variedad; la edad de los cafetales; el número de árboles por hectárea (densidad); la adopción de prácticas correctas y eficientes en el proceso productivo; y la ubicación de cultivos en zonas óptimas. Los principales instrumentos para desarrollar estas políticas eran el servicio de extensión, los resultados tecnológicos de CENICAFÉ e incentivos a la renovación.
} 
empresariales de producción en la lógica de libre mercado defendida por la federación.

La insignificante participación de los pequeños y medianos cultivadores en cuanto hace referencia al volumen de producción nacional los coloca en una difícil situación y alta vulnerabilidad, quedando expuestos a la desaparición del espectro productivo, por lo menos en calidad de propietarios y productores directos. [...] De hecho, por este motivo ya se está observando la sustitución de cultivos en algunas zonas cafeteras. (Rincón, 2006, pp. 26-27)

La lucha por recursos dispuestos por parte de la federación fue dejando paulatinamente por fuera a medianos y pequeños caficultores de esta nueva etapa del mercado cafetero. Marginación que en términos regionales significó el desplazamiento de sistemas productivos cafeteros que, como los del municipio de Samaná, presentaban dificultades en cuanto a la configuración de su estructura productiva. Para el año 2002 se estimaba que en el Oriente de Caldas existían 52.091 fincas cafeteras, con un área sembrada de más de 94 mil hectáreas. Según los datos del sistema de información cafetera del Comité de Cafeteros de Caldas (2002), casi en el $60 \%$ de las fincas, el área cultivada era menor a una hectárea y únicamente 2,2\% superaban las 10 hectáreas. Lo que indicaba que un poco más del $97 \%$ de la estructura productiva cafetera de la subregión se componía de pequeños caficultores y medianos productores, sector que quedó en desventaja para participar en la distribución de los recursos en virtud de los ajustes al modelo productivo, y por lo tanto, en condiciones desfavorables en cuanto a competitividad y distribución del ingreso. (Leguízamo, 2011)

Adicionalmente, durante toda la década de 1990 la federación estaba siendo desplazada paulatinamente por agentes de comercialización privado ${ }^{20}$ que simultáneamente aumentaban su capacidad de negociación con los países productores. Por esta situación y bajo la lógica de disminución de costos, la federación varió hacía el 2001 su política de comercialización. La garantía de compra de café a través de la infraestructura institucional como cooperativas, puntos de compra y bodegas, aseguraba un comprador fijo al productor y le brindaba un fácil acceso a los puntos de compra más cercanos a su finca. Con el desmonte del subsidio al sistema de compra, las cooperativas debían generar un margen excedente que les permitiera cubrir sus gastos administrativos, es decir, les ordenaba asegurar fuentes de ingreso

\footnotetext{
${ }^{20}$ Según la Comisión de Ajuste (2002), entre 1995 y el 2000, la federación pasó de exportar el 38.5\% a $36.2 \%$ del café; mientras empresas privadas pasaron de exportar el $61.5 \%$ a $63.8 \%$, respectivamente; cayendo igualmente su nivel de compra del $50 \%$ al $33 \%$.
} 
autónomas. El excedente derivaba de un descuento por libra exportada al productor, y este porcentaje variaba de acuerdo con la ubicación de éste, siendo más alto en las regiones extremas. Así, la necesidad de garantizar fuentes de ingreso llevó a la articulación de las cooperativas con la empresa privada para la comercialización del café, o a tomarlo como negocio propio. Esta fusión demandaba a las zonas productoras condiciones de producción competitivas en términos de disminución de costos por mano de obra, condiciones climáticas favorables para el cultivo de Cafés especiales y ventajas infraestructurales. (Leguízamo, 2011)

Estos cambios en el sistema de comercialización obligaron a los cultivadores del municipio a cumplir con requisitos de producción que les dificultaba a ellos y a las cooperativas lograr un margen de acumulación; esto por tratarse de las zonas más apartadas de los principales centro de intercambio de la región, por presentar un grado de humedad relativa alto que disminuye la calidad del café, por el daño de las plagas, por poseer condiciones topográficas difíciles para el desarrollo vial y, como veremos a continuación, verse afectado por el conflicto armado. Para la caficultura de la localidad, esta transformación en el sistema de comercialización condujo a la profundización de su histórica marginación productiva, deteriorando las condiciones de mercadeo de sus áreas rurales, y por ende, afianzando el proceso de pauperización de numerosas familias campesinas ${ }^{21}$.

Un caficultor de Samaná relata lo que fue ese proceso de crisis para los cultivadores del municipio:

Después de que llegó la broca, esa sí nos tiró a tierra. Porque yo era socio de la cooperativa de caficultores y cualquier día llevé un café y no sirvió, no lo recibieron. Entonces a un señor (...), comprador de café, le dije: 'Don Humberto, me compra este cafecito'. Me dijo 'Hombre, ¿por qué no se lo compraron en la Cooperativa?'. Le dije 'Hombre, no sé porqué'. Yo me disculpé con cualquier cosa. Dijo 'Yo se lo compro, pero barato' (...) Y ahí ya comenzamos para atrás oiga. Hubo gente que les producía infarto, porque dígame, un cafetero con deudas y llevando mala calidad, qué le iban a dar por eso.(Entrevista realizada a Don Víctor en 2014)

De manera que la crisis cafetera llevó a un proceso de transformación de la institucionalidad y del modelo productivo cafetero que se caracterizó

\footnotetext{
${ }^{21}$ Según el informe de Desarrollo Humano (2002), entre los años 1997 y 2002 en el municipio de Samaná los ingresos percibidos por los trabajadores agrícolas estaban por debajo del salario mínimo. En conjunto, el municipio presentaba un porcentaje de pobreza extrema del $61.7 \%$ (aumentando siete puntos en este periodo), y de hogares en la indigencia del $24.3 \%$ (aumentando cinco). El índice de Necesidades Básicas Insatisfechas (NBI) era del $32.93 \%$, por encima del promedio departamental de $24.30 \%$.
} 
por el abandono de las funciones de asistencia social y productivas, especialmente de las regiones periféricas al mismo, y por la marginación en la aplicación de las políticas de diversificación y ampliación de la base económica de gran parte de municipios como Samaná. Con esto se restringieron las posibilidades comerciales de la localidad y se debilitó la presencia institucional, traduciéndose a su vez en la disminución de los ingresos de los caficultores y el deterioro de las condiciones de vida de la población campesina.

Se aprecia cómo la crisis y la subsiguiente transformación del modelo productivo cafetero profundizaron el rezago en términos del desarrollo económico y social de Samaná frente a otros municipios cafeteros. Pero además, generaron unas condiciones que, como veremos en el siguiente apartado, favorecerían la conversión de cultivos de café por los de coca, y con ello la penetración del narcotráfico y la agudización de la guerra en este territorio. En palabras de John Jairo Rincón:

El deterioro de las condiciones de vida de los productores cafeteros y el desempleo, sumado a la monodependencia económica derivada de la actividad cafetera, a la disminución de precios en el mercado internacional (y nacional) y las dificultades económicas para acceder a los procesos de reconversión productiva agenciados por la Federación, la empresa privada y el Estado, se constituyen entre otros, en algunos de los factores que han venido agenciando la transición productiva, posibilitando el tránsito del cultivo del café al de coca y amapola. (Rincón, 2006, 54)

Además de la desestructuración del modelo cafetero descrita arriba, los otros factores que explican el paso a la economía de las drogas ilícitas son la poca presencia estatal, la intensificación de los procesos migratorios de población empobrecida y la expansión del conflicto armado sobre gran parte del territorio del municipio. A continuación, se abordarán estos aspectos.

\section{3- "El que tiene las armas manda": presencia estatal, in- serción guerrillera y cultivos de coca}

En el apartado anterior se caracterizó el modelo productivo cafetero en Caldas y la forma como dicho modelo implicó el rezago en términos de desarrollo social y económico del municipio de Samaná. En esta localidad, el capital acumulado en la economía cafetera no permitió el tránsito por parte de los productores a otras actividades económicas ni la consolidación 
de un sólido mercado local que llevara a la densificación de las relaciones comerciales con otras regiones y al fortalecimiento de la infraestructura vial. Con la venida de la crisis del sector en sus múltiples manifestaciones (baja de precios, plagas, etc.) y la posterior reorientación del modelo que agenciaba la federación, la situación de marginación productiva de la localidad se agudizó hasta el punto de comprometer la supervivencia de los caficultores. Estas fueron las condiciones económicas que, junto con los otros elementos que se abordarán en esta parte del texto, constituyen la amalgama de factores que permite explicar por qué y cómo un municipio cafetero incursiona en la economía de la coca. A continuación se examinará lo relativo a la presencia del Estado en la localidad, la inserción de los grupos armados en la región y el proceso mismo de diversificación de la producción agrícola para incluir la coca.

\section{Algunas consideraciones sobre la presencia del Estado en Samaná}

A pesar de la importancia que varios autores le han atribuido al café en términos de su rol en la estabilidad de las instituciones del país ${ }^{22}$, no existen trabajos sobre la construcción de Estado en la región cafetera, ni sobre la relación entre el gremio y ese proceso. A falta de estudios, algunos académicos solucionan el problema recurriendo a la idea vaga de que "la Federación Nacional de Cafeteros era el Estado dentro del Estado en la región", es decir, una especie de "sustituto" del Estado. Como es evidente, en este artículo no es posible ocuparse de ese asunto, pero sí se presentarán algunas claves sobre la presencia del Estado en el municipio de Samaná a partir del trabajo de campo realizado.

Las dificultades del Estado colombiano para garantizar el control de la totalidad del territorio nacional han sido evidentes a lo largo de la historia. La presencia diferenciada de las instituciones del Estado, que son la base para que exista una regulación de las relaciones sociales por parte de un poder central, ha sido una de los rasgos claves que diferentes académicos han asociado a fenómenos como el conflicto armado y las economías ilícitas en diferentes regiones del país (Bolívar, González y Vásquez, 2002). En ese sentido, instituciones como las que se encargan de garantizar el monopolio de la coerción legítima y el imperio de la ley son fundamentales para

\footnotetext{
${ }^{22}$ Gonzalo Sánchez, respecto a la crisis cafetera, señalaba que "la pregunta es aún más apremiante si tenemos en cuenta el papel determinante que ha jugado el café no sólo en la economía sino también en la construcción de la estabilidad institucional colombiana. Porque no hay que olvidarlo: en Colombia, la economía y la sociedad cafeteras le otorgaron a las instituciones una estabilidad sorprendente y la capacidad de resistir los embates de los ciclos de violencia que han desgarrado el país". (Sánchez et al, 1999, p. 17).
} 
que el Estado logre controlar el territorio y la población, evitando que se desarrollen actividades que atentan contra la normatividad existente y que otros grupos o individuos se arrojen el derecho de regular la vida de los miembros de ese Estado. Justamente, esas instituciones son inexistentes o ineficaces en las zonas consideradas de frontera o periféricas, territorios donde operan los distintos grupos armados ilegales y donde se llevan a cabo actividades económicas de corte ilegal. En el caso del municipio objeto de estudio, se puede decir que este constituye un ejemplo de una región de frontera interna.

En Samaná, las entidades públicas (o que cumplen funciones de ese tipo) que para finales del siglo pasado tenían mayor importancia eran la UMATA (Unidad Municipal de Asistencia Técnica) y la FNC, a través de los distintos entes vinculados a ella. La primera es una entidad oficial prestadora de asistencia técnica y de transferencia de tecnología a pequeños productores agropecuarios (Leguizamo, 2011, p. 110). La federación, por su parte, era el principal órgano de inversión y apoyo productivo. La cooperativa se encargaba de la comercialización del grano, el Banco Cafetero otorgaba los créditos a los productores y el Comité Municipal era el encargado, entre otras cosas, de implementar los proyectos de inversión y coordinar la asesoría técnica; así constituían la red institucional cafetera en el municipio.

Los márgenes de ganancia que dejaba la actividad cafetera permitían a la institucionalidad un abanico amplio de líneas de inversión de capital que trascendían las necesidades de exportación y producción del grano. La inversión social y en infraestructura como escuelas, puestos de salud, acueductos, electrificación, y mantenimiento de carreteras, evidenciaban este hecho. Aunque la situación de Samaná respecto a los servicios públicos no era la mejor ${ }^{23}$, es claro que la federación cumplía, hasta antes de la crisis, la función estatal de proveer de bienes y servicios públicos al municipio ${ }^{24}$. Sin embargo, hasta aquí llegaban las labores que adelantaba la FNC en la localidad; esta no era ningún "sustituto del Estado".

\footnotetext{
${ }^{23}$ Además de las malas condiciones en que se encontraba la infraestructura vial, la situación de los otros bienes y servicios públicos no era tampoco la mejor. De acuerdo con el Informe de Desarrollo Humano (2002) de una población de casi 25.000 habitantes, sólo 13.863 personas sabían leer y escribir, significando la cobertura más baja en el nivel de educación superior y una de las más reducidas en el secundario en el departamento. La cobertura en telefonía en las áreas rurales era del $0.34 \%$, por debajo del promedio departamental de $8.57 \%$; la cobertura en servicio de agua potable y saneamiento básico (acueducto) llegaba al 32.66\% en las áreas rurales, mientras el promedio departamental mostraba un $52.22 \%$ de extensión del servicio; la infraestructura de alcantarillado cubría el $2.49 \%$ del área rural, por debajo de la media departamental del 36.09\%.

${ }^{24}$ Ver en los Anexos el fragmento de la entrevista realizada a un caficultor en el que narra el proceso por el que logró la electrificación y pavimentación de su vereda al participar en el comité municipal y contar con el apoyo de un político regional.
} 
Fuera de las entidades con funciones económicas y técnicas orientadas a la producción agrícola, en la cabecera municipal de Samaná hacían presencia la Caja Agraria, la Registraduría Nacional del Estado Civil y dos juzgados promiscuos. El desempeño de la justicia, como anotan García y Espinosa (2013), es una dimensión importante para dar cuenta de la capacidad institucional local porque es un componente central del Estado y del poder político, así como un factor esencial en la definición y solución de los conflictos sociales e institucionales, y es parte importante de la capacidad del Estado para someter a los actores que lo desafían (García y Espinosa, 2013, p. 45). En esos términos, la eficacia de la justicia es vital para saber en qué medida los habitantes de un territorio determinado están en disposición de actuar conforme a los mandatos de la autoridad estatal y a no desafiarla, convirtiéndose así en uno de los factores que explican la presencia de grupos armados ilegales y de economías ilícitas.

Para evaluar el desempeño de la justicia local, los autores emplean dos indicadores: la presencia de funcionarios judiciales en el territorio y la eficacia del sistema en la persecución de homicidios. Por las dificultades para acceder a la información sobre el desempeño del aparato judicial del municipio estudiado, aquí contemplaremos sólo el primer indicador. Samaná, como se dijo, contaba para finales de los años noventa con dos juzgados municipales promiscuos. De acuerdo con eso y atendiendo a García y Espinosa, en la localidad no había el tipo de jueces que debían tener presencia en todo el territorio del país sin importar el tamaño del municipio ${ }^{25}$. Tampoco existía una unidad local de la Fiscalía, es decir, que un funcionario con sede en otro municipio se tenía que desplazar a Samaná para investigar y, si era el caso, actuar judicialmente. Los autores señalan que la falta de operaciones fijas en un territorio significa en la práctica, con mucha frecuencia, la inoperancia de la Fiscalía en ese municipio (García y Espinosa, 2013, p. 48). Se puede ver que, al menos en lo que tiene que ver con la presencia de funcionarios judiciales, la posibilidad de administrar justicia en Samaná era bastante limitada; es decir, el imperio de la ley no estaba a la orden del día.

No era sólo la falta de jueces y de funcionarios de la Fiscalía lo que definía la ausencia estatal en el municipio, también faltaban quienes hicieran cumplir la ley. De acuerdo con los testimonios de algunos campesinos entrevistados, la fuerza pública no hacía presencia en el territorio desde hacía 10 ó 15 años antes de que ingresaran los efectivos del ejército y la

\footnotetext{
${ }^{25}$ Hacen alusión a los jueces de menor jerarquía: penales municipales, penales municipales para adolescentes - control de garantías -, penales municipales ambulantes - Bacrim, control de garantías -, jueces civiles de pequeñas causas, jueces laborales de pequeñas causas, jueces civiles municipales, jueces promiscuos municipales y jueces promiscuos del circuito (García y Espinosa, 2013, p. 47).
} 
policía a combatir a las Farc. La función del Estado de proveer seguridad era casi inexistente en la amplia zona rural de Samaná. Este fragmento de la entrevista hecha a un caficultor de la zona que comenta el reclamo que le hace a un comandante guerrillero del frente 47 de las Farc, luego de que un grupo de milicianos le robaran un armamento que guardaba, es sugestivo respecto a la necesidad de los campesinos de proveerse su propia seguridad:

(...)Y me dijo [se refiere a "Mocholo", el comandante guerrillero] ' $¿ Y$ usted de a dónde sacaba tanto parque [armamento]? (...)-'Es que yo cada cuatro meses compro parque, a mí me venden parque' le dije. - '¿A dónde?' preguntó "Mocholo". (...) En la base [militar], porque esas armas tienen papeles. Y no vaya a creer que es pa' pelear con ustedes, porque allá el sargento cuando uno le compra las armas le dice 'vea, estas armas es pa' que ustedes se defiendan de esos rateros en las fincas, pero esto no es pa' ustedes pelear con la guerrilla. Esto es $\mathrm{pa}^{\prime}$ que se defiendan de esos rateros que van a robarles allá a ustedes lo que están trabajando' (...) Y eso le dije yo a Mocholo: 'Yo voy allá y me venden 200 tiros de revólver y 400 de escopeta, y yo vendo eso y a mí me da platica'. (Entrevista realizada a Don Gamaliel en 2014).

La labor que realizaba Don Víctor cada cuatro meses de comprarle armamento al ejército para venderlo entre el resto de agricultores que necesitan defenderse de los "rateros" que rondan las veredas, es bastante diciente respecto a la poca presencia del Estado y su incapacidad de asegurar la vida y los bienes de los habitantes de las zonas rurales de Samaná. Esto y la ausencia de funcionarios judiciales son características de una zona de frontera interna cercana a los grandes centros urbanos, donde la precariedad institucional es una garantía, entre otras cosas, de la presencia de grupos guerrilleros y de cultivos de coca (García y Espinosa, 2013).

En tal sentido se puede afirmar que la fuerte presencia del gremio cafetero garantizó la provisión (parcial) de algunos bienes y servicios públicos, no sólo relacionados con la producción del grano; pero no fue realmente un "sustituto del Estado". Las instituciones encargadas de funciones claves que determinan la forma en que el Estado controla un territorio, como lo son el monopolio de la coerción y la capacidad de aplicar la ley, eran muy precarias. De tal forma, las condiciones materiales (económicas y políticas) estaban dadas para que las Farc, y luego los paramilitares, llegaran al municipio de Samaná en el oriente de Caldas y se comenzara un proceso de siembra de cultivos de coca en donde antes sólo se veían cafetales. De esos procesos se tratarán los siguientes subtítulos. 


\section{La configuración de una zona de conflicto armado}

Las Farc ingresaron a la región del oriente de Caldas a mediados de la década de los noventa, en plena crisis cafetera, provenientes del suroriente antioqueño. En la VII conferencia de la organización subversiva (1982) se constituyeron nuevos frentes que operarían en Antioquia y Chocó, entre ellos el frente 47 que en un principio operó en el Magdalena Medio y luego, en los noventa, se asentó en el oriente lejano de Antioquia y el oriente de Caldas (www.verdadabierta.com, 2014). El objetivo del grupo insurgente en esta región caldense era crear una zona de retaguardia que les permitiera ejercer influencia en el Magdalena Medio controlado por los paramilitares, al tiempo que abrir corredores de movilidad desde esa región hacia Antioquia y el Pacífico, llegando por el Chocó (Ver Mapa 3) (Observatorio del Programa Presidencial de DH y DIH, 2005).

Las condiciones topográficas de la región permitieron que, de acuerdo con un informe de riesgo de la Defensoría de la época, las Farc consolidaran una red de trochas que les facilitó la movilidad hacia el resto de Caldas, el norte de Tolima, el Magdalena Medio y el Suroeste antioqueño (www. verdadabierta.com, 2014).. Sumado a esto, la poca presencia de la fuerza pública y de las instituciones estatales en el territorio rural de la localidad, hizo de la región montañosa de Samaná un teatro de operaciones ideal para que incursionara el frente 47 de las Farc.

En la etapa de inserción en el territorio, los insurgentes realizaron diferentes acciones que tuvieron como punto de partida el año 1993. En esa fecha se destacan dos atentados de esta agrupación contra instalaciones de fincas en el corregimiento de Florencia. En los años venideros se producen hostigamientos contra la poca policía que había en el municipio, hasta que en 1996 incursionaron en el mismo corregimiento de Florencia y atacaron el puesto de Policía, hiriendo a 3 agentes y 6 civiles. En noviembre de 1997, en una vía del municipio, atacaron a una patrulla de la policía cuando transportaba la nómina de pago de los agentes del puesto, los cuales fueron hurtados, y asesinaron a un suboficial y un patrullero ${ }^{26}$. Finalizando la década, en 1999, combatientes del frente 47 volvieron a arremeter contra el comando de policía del corregimiento de Florencia, destruyendo a su paso la Caja Agraria y la iglesia ${ }^{27}$. Las acciones, que terminaron por minar el ya débil poder coercitivo del Estado, dejaron a Samaná bajo el dominio de esta agrupación guerrillera (Observatorio..., 2005).

El asentamiento de las Farc en la localidad implicó una relación directa con la población que habría de proveerle, por la vía de la coacción o

\footnotetext{
${ }^{26}$ Observatorio del Programa Presidencial de DH y DIH (2005). Dinámica reciente de la confrontación armada en Caldas.

27 “Mujer murió en iglesia atacada por las Farc en Florencia”. El Tiempo. Publicado el 20/05/1999.
} 
no, los suministros, el apoyo logístico, los recursos y hasta los combatientes para continuar en la confrontación. Una parte de los recursos provino, según la Fiscalía, de los secuestros y extorsiones que recayeron, en su mayoría, sobre ganaderos y comerciantes ${ }^{28}$. No obstante, portales como Verdad Abierta reportan testimonios de caficultores y jornaleros que tenían pagar extorsiones y a quienes les eran robados sus animales y bienes. Esta información contrasta con los testimonios recolectados en el trabajo de campo en los que los campesinos aseguraban que la guerrilla no se apropió de sus bienes ni les cobró extorsiones, si tenían que coger algún bien de los campesinos lo pagaban de inmediato o días más tarde. "A nosotros pa' que, hay que decir la verdad que la guerrilla no nos robó nada" comentó un caficultor entrevistado ${ }^{29}$.

Respecto a los pobladores del municipio que terminaron ingresando a las filas de la guerrilla, bien sea como combatientes o como milicianos, es claro que la crisis de los caficultores jugó un papel importante en ese proceso. Fuera de los comandantes guerrilleros que eran de Samaná, como alias "Pipa" y alias "Nodier", por las filas de la insurgencia desfilaron familias completas de la zona que se volvieron combatientes $^{30}$, y varios jóvenes que terminaron como milicianos. Sólo entre los menores de edad se cuentan 74 casos de reclutamiento ${ }^{31}$.

Algunos jóvenes fueron convencidos de que hicieran parte de los grupos. De pronto por la misma situación que se vivía en ese momento, entonces los jóvenes eran presa fácil de dejarse influenciar por los grupos para que hicieran parte de las milicias. Como había una crisis tan fuerte económicamente, pues ellos veían de pronto una forma de al menos subsistir de algo. (Entrevista realizada a Don Arley en 2014)

Sobre sus hijos que abandonaron el municipio y viven hoy en las ciudades Don Víctor señala que: “Pues ellos, como estaban tan jóvenes, me dio miedo que se metieran a algún grupo y les dije 'váyanse yendo de aquí que de pronto en cualquier momento los conquistan'". Se le preguntó si se llevaban a los jóvenes de la región y dijo "A veces. Se ponían a tomar trago con ellos, y ellos (los jóvenes) viendo tanta plata. Usted sabe que la plata

\footnotetext{
${ }^{28}$ De hecho, los informantes eran enfáticos en diferenciar el tratamiento que recibieron de la guerrilla del que le dieron los paramilitares. Los últimos les cobraban vacuna por el ganado y por la finca, y les robaban sus animales, enseres, los cables de luz y "hasta las paredes para hacer comida". En los anexos se incluye el fragmento de una entrevista en el que se expresa las formas variadas en que los actores armados se relacionaban con los campesinos de Samaná.

29 "Karina', a responder por 143 crímenes en Caldas y Antioquia" www. verdadabierta.com. Publicado el 24/01/ 2014.

30 “Nos cansamos de sufrir y por eso nos desmovilizamos". La Patria. Publicado 31/01/2008.

${ }^{31}$ Ibídwww.verdadabierta.com, 24/01/2014.
} 
es codiciada, ya se van ilusionando y dicen 'hombre, es este el camino'" (Entrevista realizada a Don Víctor en 2014).

El miedo a que las Farc "conquistaran" como milicianos a los jóvenes del sector rural de Samaná provenía principalmente de la atracción que generaba el dinero en unas personas cuyas familias pasaban serias penurias económicas, pero este dinero no provenía de un "sueldo" que pagara la guerrilla (como demuestra Francisco Gutiérrez (2003), las Farc no pagaba a sus integrantes), sino de los recursos que por su cuenta pudieran conseguir los milicianos, robando y extorsionando en nombre de la insurgencia. El relato de un caficultor que se reproduce a continuación, muestra los problemas que tuvieron los comandantes de las Farc en la zona para controlar a los milicianos reclutados allí:

Un tipo se metía de miliciano de la guerrilla y eso vivía era tomando trago y robando a la gente en nombre de la guerrilla. Que la guerrilla mandó a decir esto, y robe. Y después la guerrilla los mataba por ladrones. (...) El hijo de doña Fabiola le pasó eso, (...) una vez le pidió a un señor ahí en el pueblo que hace ocho días le había mandado una plata a Nodier, millón y medio, (...) y el señor le dijo 'Sí, voy a ver si los consigo, en un ratico venga por ellos' Y ahí mismo llamó a Nodier y le dijo: ‘Oiga cómo es esto comandante, yo hace ocho días le mandé una platica a usted y aquí este vino y me pidió otros 300'. Nodier le respondió: '¿Quién se los pidió?', (...) ‘No se los vaya a dar a ese hijueputa que yo no le he mandado a pedir nada'. Y a los ocho días lo bajaron por allí de un carro y lo mataron ahí mismo. (...) Nodier le comentó 'nosotros en parte tenemos la culpa porque nosotros formamos esas milicias, pero eso con esos milicianos se nos ha salido a nosotros de las manos. Esos hijueputas están robando, se pusieron fue a robar y usted mismo ve que hemos matado a varios por eso, y vamos a tener que seguir matando porque hay muchas quejas'. (Entrevista realizada a Don Gamaliel en 2014)

Sin embargo, el deterioro en las condiciones de vida a causa del impacto de la crisis cafetera en el municipio no era el único factor que explicaba la vinculación o el apoyo de los lugareños a las Farc. Fueron múltiples las motivaciones que impulsaron a los habitantes de Samaná a respaldar a la guerrilla, entre ellas se tienen las simpatías ideológicas, las tensiones familiares, los descontentos políticos, y hasta motivos banales como la posibilidad de utilizar el poder coercitivo de la guerrilla para zanjar disputas personales ${ }^{32}$.

\footnotetext{
32 Se tiene el caso de un cura del municipio que brindó apoyo a la guerrilleros y a cambio pidió que estos amenazaran a un profesor de colegio que se había enterado y había esparcido entre la comunidad la
} 
Así las cosas, las dificultades del Estado para controlar las zonas rurales de municipio en lo que se refiere a provisión de seguridad y administración de justicia, la agudización de la situación económica de las familias caficultoras, las condiciones topográficas que facilitaban el desplazamiento de las tropas y, en general, el aislamiento de Samaná de los centros económicos y políticos regionales producto de su marginación histórica como región productora de café, constituyeron el escenario propicio para que las Farc, en esta primera fase de configuración de Samaná como territorio de confrontación armada, se erigiera como autoridad en la zona rural de la localidad cafetera.

Los subversivos citaban a la comunidad a reuniones y les imponían reglas y prohibiciones, y la gente temerosa no reclamaba, además de que no había ante quién quejarse, pues no había por allí policía ni ejército ${ }^{33}$. “Nos impusieron la causa. Nos dijeron: acá no puede haber ni marihuaneros, ni ladrones, ni violadores. A los sapos: 'yuca'; es decir, la muerte" ${ }^{34}$ relató el habitante de una vereda. El poder que ejercía la guerrilla, y más tarde los paramilitares, sobre la población civil lo resumen varios de los campesinos entrevistados bajo el simple principio de que "el que tiene las armas manda".

El dominio del territorio y de la población durante más de cuatro años por parte de las Farc se constituyó en otro de los factores determinantes para que se empezara a sembrar coca en diferentes corregimientos de la localidad como veremos en seguida; de esa manera se dio inicio a otra etapa del conflicto en la región.

La segunda fase de la confrontación armada en Samaná inició en los años 2000, cuando la expansión de los cultivos de coca dinamizó el poder de la organización guerrillera, pero al mismo tiempo atrajo la atención de las autodefensas, que empezaron a movilizarse desde el valle del Magdalena y desde el sur de Antioquia hacia el norte de Samaná. El incremento en la intensidad de la guerra generó la intervención de la fuerza pública. (Observatorio..., 2005, p. 17). La disputa por el control de los cultivos ilícitos en la región exacerbó los costos y perjuicios que recayeron sobre unos campesinos cafeteros empobrecidos, quienes se vieron obligados, en medio del fuego cruzado, a abandonar sus cosechas y viviendas para salvar la vida. En las conclusiones se regresará sobre las consecuencias de la guerra sobre esta población, pero ahora se describirá el proceso de inserción de la economía de la coca en la localidad cafetera.

\footnotetext{
noticia del romance del sacerdote con una docente. "El cura Reinoso, ahora investigado por homicidio". La Patria. 13/10/2014.

33 "Todos mataron a Samaná". www.verdadabierta.com 26/02/2014.

${ }^{34}$ Ibíd. www.verdadabierta.com 26/02/2014.
} 


\section{Los cultivos ilícitos y las migraciones provenientes de zonas cocaleras}

Hasta aquí se han presentado el conjunto de condiciones que generaron un contexto favorable para que los campesinos productores de café empezaran a cultivar coca. En las páginas que restan se revisará ese proceso con más detalle.

De acuerdo con información de la Defensoría del Pueblo y el Observatorio del Programa Presidencial de DDHH y DIH, los cultivos de coca aparecieron en Samaná, aproximadamente, en 1999. Sin embargo, hay registros de que años atrás grupos de narcotraficantes provenientes de Antioquia estaban sembrado y procesando coca en el corregimiento de Florencia $^{35}$, al norte del municipio. En todo caso, es a finales de la década de los noventa que los cultivos se extienden a otros corregimientos como Encimadas, San Diego y Berlín. Para entender esa expansión de los cultivos proscritos, hay que atender a dos fenómenos que se dieron paralelamente: por un lado, el regreso al municipio de campesinos que habían migrado tiempo atrás a las tradicionales regiones cocaleras y volvían socializados en todo lo referente a esa labor agrícola y sus "beneficios", y, de otra parte, la presión y los incentivos que las Farc, y luego los paramilitares, ofrecían a los campesinos para que sustituyeran los cafetales y otros cultivos de pancoger por la coca.

La disminución drástica de los ingresos de los productores de café y la agudización de la situación socioeconómica de las familias campesinas producto de los impactos más severos de la crisis sobre una región relegada tempranamente del modelo productivo del café pusieron en marcha un proceso de migración de los agricultores hacia las ciudades y hacia zonas donde pensaban llevar una mejor vida. Entre los destinos de los caficultores y demás trabajadores agrícolas estuvieron la región del Catatumbo y los

\footnotetext{
${ }^{35}$ El relato proviene del miembro de una familia de grandes propietarios de tierra que, al parecer, entró en una guerra a muerte con narcotraficantes porque se negó a participar en el negocio del tráfico de drogas con los hombres del paramilitar Hernán Giraldo. “Todo empezó hace 5 años. Hernán Giraldo Serna le envió un mensaje a la familia a través de un primo suyo de nombre Ramón (...) quería que nos asociáramos para sembrar marihuana y coca. Nos dijo que nosotros sólo teníamos que poner las tierras y que yo debía hacer el contacto con las autoridades para que nos permitieran trabajar tranquilos. Ramón decía que debíamos aprovechar que yo era presidente del Concejo de Samaná y que había sido diputado a la Asamblea de Caldas. Sin embargo, a pesar de que Hernán, mis otros hermanos y yo nos negamos a aceptar, se empezó a sembrar coca. Primero fue en La Cabaña, una finca que está en la vereda El Congreso y que nosotros le habíamos vendido a Alonso Granada Jaramillo. Entonces mi hermano, Hernán Medina, los denunció y las autoridades intervinieron. En esa operación fueron capturados Ramiro Granada Henao y otros dos hombres que habían llegado desde Medellín (...) Luego la Policía decomisó pasta de coca y toda la marihuana que tenían sembrada. Ahí empezaron las amenazas. Nos dijeron que nos iban a bombardear la casa de la finca y que nos iban a matar a todos". "Los Medina. Historia de un exterminio". El Tiempo, 17/08/93.
} 
departamentos de Caquetá y Putumayo ${ }^{36}$, zonas en pleno auge coquero donde los migrantes pudieron insertarse como mano de obra para los cultivos proscritos. Al parecer, luego de las fumigaciones con glifosato a las matas de coca en esas zonas de frontera, los agricultores provenientes de Samaná regresaron a su tierra llevando consigo las semillas, los conocimientos respecto a la producción y el entusiasmo que generaba un producto que, a diferencia del café, si les "dejaba algo".

Pues estuvieron en otros lados y de allá se venían entusiasmados, que la situación fue tanta que la gente se desplazaba a otras zonas coqueras. Y como allá la plata eso es por costalados, la gente se anima, esa es la vaina (...) en ese entonces era el apogeo de la coca y se vendía fácil y le decían a uno que igual a esa mata no hay nada. Entonces ya venían y decían 'hombre, eso nos va tocar es meterle a eso, ese café no vale nada' o si no eso [la coca] no hubiera llegado por aquí (...) Porque tuvieron la situación tan brava de la broca del café, dijeron que donde se cogía 20, 30 cargas de café, daba el doble en coca. Y que siempre demandaba gasto, pero era rentable. Qué opina nosotros vendiendo café a 200, 300 mil pesos y ellos recibiendo por un kilo [de coca] 2 ó 3 millones de pesos. (...) Entonces la gente se iba entusiasmando, porque aquí esto lo maneja es la plata (Entrevista realizada a Don Víctor en 2014)

A finales de los noventa salió mucha gente del pueblo (...) Resulta que se iban a trabajar a las selvas de Florencia para dentro, en el departamento del Caquetá. (...) Mucha gente fue a raspar coca, (...) estuvo raspando en Caquetá, Putumayo (...) y la gente venía entusiasmada. Ya en ese momento se empieza a conocer de cierta manera los beneficios inmediatos de la producción (...) iporque era plata al instante! La gente comúnmente espera ocho meses para una cosecha de café, ¿cierto?...y esa gente venía diciendo que usted producía [coca] constantemente, cada tres meses (...) En el pueblo se estaba viviendo, y siempre se ha vivido, un periodo de inestabilidad económica, porque los momentos prósperos del pueblo han estado sujetos a eventos como el tema de la bonanza cafetera...y ya ahorita después con el tema de la coca, pero en realidad la gente estaba pasando necesidades y todo el mundo quería conseguir algo, todo mundo quería trabajar... (Entrevista a un cocalero. Citada en: Leguizamo, 2011)

Los dos testimonios citados son claros respecto a lo sucedido en la ruralidad de Samaná. Las personas que llegaban luego de haber

\footnotetext{
${ }^{36}$ Resolución Defensorial Nacional No. 028. "La crisis cafetera y las fumigaciones en el departamento de Caldas". Defensoría del Pueblo. Manizales: 2003.
} 
participado como raspachines o cultivadores de coca les contaban a sus coterráneos los beneficios que traía el sembrar la mata en términos de su mayor productividad y del precio tan alto en que se vendía. Las noticias de los recién llegados, como es evidente, tuvieron eco en varias familias de caficultores empobrecidos que vieron una oportunidad de mejorar sus ingresos y que, por tanto, decidieron diversificar su producción para incluir la planta con la que se fabrica el alcaloide. Pero para que se diera la sustitución de café por coca, no sólo bastaban las disposiciones subjetivas de los campesinos de Samaná entusiasmados por la "plata al instante", se requería además que existiera la posibilidad de hacerlo, es decir, una zona sin control del Estado y, adicionalmente, grupos capaces de organizar y regular la actividad económica de la droga. Como se mencionó, grupos de narcotraficantes pudieron haber ejercido esa función por un tiempo, pero las Farc y los paramilitares terminaron por tener el control de los cultivos.

Las palabras de un cultivador de coca citadas por Leguizamo (2011, p. 119) confirman lo que hasta aquí se ha dicho respecto a la relación entre la poca presencia estatal, para ese entonces minada además por el accionar insurgente, y la siembra de coca en la localidad:

Había una gente, en San Diego, que era de Antioquia (...) que estaba produciendo en esos momentos (1998), ya la policía no estaba en San Diego (...) El man estaba produciendo coca, tenía cultivos de coca en la frontera con Antioquia (...) ¿Por qué por allá? ¡Eso era una tierra inhóspita! (...) Entonces eso era una tierra sin control, sin control político, el chiste era que allá no entraba ni el ojo de dios. Este otro territorio aquí más al occidente que era ya limitando con el municipio de Norcasia, (...) había más control policial y del ejército, entonces no había posibilidad de iniciar unos cultivos por esa parte.

Ahora bien, una vez las Farc se consolidaron en el territorio, coincidieron el retorno de aquellos que llegaban de las regiones productoras de coca y hablaban a los otros campesinos de las "bondades" de este cultivo con las presiones e incentivos que el grupo guerrillero les ofrecía a los caficultores para que se dedicaran al cultivo ilícito. En las reuniones a las que convocaban a los habitantes de las veredas para definir las normas que debían cumplir, empezaron también a decirles que tenían que sembrar coca y el que no lo hiciera tenía que desocupar sus tierras. Con un cuaderno en la mano pasaban preguntándole a los campesinos: “¿Cuántas va a sembrar usted?", y la gente apuntaba cuantas matas iba a cultivar (Entrevista realizada a Don Gamaliel en octubre de 2014). Pero también vinculaban a los caficultores ofreciéndoles costear los abonos y todo lo que hiciera falta, además de proveerles la vigilancia a los cultivos (Entrevista realizada a Don 
Víctor en octubre de 2014). Por lo que, bien fuera presionados o no, algunos caficultores y campesinos empobrecidos aprovecharon la oportunidad de dedicarse a una labor que les resultaba más rentable en términos económicos, claro está, no sin terribles consecuencias y costos tanto económicos como sociales.

Con la extensión de los cultivos de coca y la instalación de laboratorios para elaborar la pasta, Samaná empezaba a desplazar la economía agroexportadora del café por la economía ilegal. Los cambios en los corregimientos y veredas asociados a este tipo de actividad económica no se hicieron esperar. Por ejemplo, en el corregimiento de San Diego, la población pasó de 2.000 a más de 6.000 habitantes. Se presentó también un alza en los costos de vida: los arriendos se triplicaron, aumentó el valor de los predios y de los alimentos. (Defensoría del Pueblo, 2003). Igualmente, dada la emergente economía cocalera controlada por las Farc, los paramilitares definieron el municipio caldense como un territorio estratégico que fue incluido en sus planes de expansión desde el Magdalena Medio. Por esa razón, los combatientes adscritos al frente Omar Isaza de las Autodefensas Campesinas del Magdalena Medio incursionan en la región en los años 2000, lo que llevó al recrudecimiento del conflicto.

Con los paramilitares disputándole el territorio a las Farc no sólo se incrementaron las presiones sobre los caficultores y demás productores agrícolas que no habían empezado a sembrar coca, sino que se extendieron y acentuaron los robos y las extorsiones sobre los campesinos. Los mismos cultivadores de coca no fueron ajenos a los hurtos ya que, de acuerdo con la información que se pudo obtener de los lugareños entrevistados, muchas veces grupos de hombres armados -presumiblemente paramilitaresingresaban a las fincas y les robaban la producción. Además, con el recrudecimiento de la guerra, la fuerza pública también entró a combatir a la guerrilla luego de años de ausencia, por lo que las Farc iniciaron la estrategia de exigir directamente al campesino 200 mil pesos por cosecha. Con todo y los problemas asociados a los enfrentamientos entre los actores armados, Samaná alcanzó a producir para 2003 casi 1.000 hectáreas de coca que implicaba un movimiento nada despreciable de 12.000 millones de pesos al mes. (Observatorio..., 2005).

Pero así como hubo cafeteros que se vieron forzados a sembrar coca por su situación económica o las intimidaciones de los grupos armados ilegales, también hubo quienes se rehusaron y tuvieron que abandonar sus tierras. El antes citado defensorial señala que para el 2003 se habían identificado varias fincas abandonadas por campesinos que no habían aceptado propuestas de sembrar dichos cultivos, razón por la cual, además, eran amenazados. Situación similar se presentó con algunos caficultores que decidieron 
erradicar voluntariamente sus plantaciones de coca (Defensoría del Pueblo, 2003). Otros que se negaron a cultivar corrieron con más suerte, como Don Víctor, que no tuvo que dejar sus propiedades por causa de las presiones:

Aquí llegaron y dijeron 'bien pueda, siembre coca' Dije no señor, esto es una zona cafetera. Porque yo era miembro principal del Comité de [Cafeteros] Samaná, entonces dije yo de eso no siembro. Entonces algunos vecinos me dijeron 'hombre cómo le queda, todos con plata y usted pobre.' Dije: 'hombre, pero ando con la frente limpia por cualquier lado. En cambio ustedes si llevan un kilo de eso están haciendo fuerza que lo van a meter a la cárcel'. (Entrevista realizada a Don Víctor en 2014)

De cualquier manera, ni los productores del grano que pasaron a cultivar coca ni los que siguieron apegados a su cultivo tradicional salieron beneficiados de todo este proceso. Con la guerra entre guerrilleros, paramilitares y ejército vinieron también los desplazamientos, la pérdida de las cosechas, el robo de los bienes, la fuga de la mano de obra jornalera y toda una serie de costos que los cultivos ilícitos nunca llegarían a suplir.

\section{4- Conclusión: el conflicto, la coca y sus consecuencias, "la otra plaga" de los caficultores}

En este artículo se ha dado cuenta del conjunto de factores que explican por qué y cómo emergió la economía de drogas en la localidad cafetera de Samaná. Contrario a las explicaciones de instituciones como la FNC que buscaban evadir cualquier responsabilidad en la tragedia de los municipios cafeteros, en este texto se argumentó que el deterioro de las condiciones de vida del campesinado cafetero y el colapso de la institucionalidad en la localidad del oriente caldense, no fueron simplemente las consecuencias de la crisis de los precios del grano sino que responden a un proceso histórico de relegación inherente al modelo de desarrollo impulsado en la región por la FNC. En ese sentido, la crisis agudizó una situación preexistente que los dirigentes del gremio habían coadyuvado a producir.

Además, en contravía de las explicaciones apresuradas y poco precavidas propuestas por algunos economistas que pretenden reducir procesos sociales complejos a esquemas básicos sustentados en una lectura estrecha de "lo económico". En este escrito se quiso proseguir con una mayor cautela y prestando más atención a la dinámica histórica y a las características económicas, sociales y políticas particulares del municipio y 
de sus habitantes. Este modo de proceder ayudó a evitar los presupuestos ingenuos y funcionó como un modo de descifrar los mecanismos concretos que relacionaron fenómenos como la crisis del modelo productivo cafetero, la dinámica del conflicto armado y el surgimiento de la economía cocalera.

De tal modo, se puede decir que en el proceso de reconversión productiva que llevó a los campesinos a reemplazar el café por la coca se imbricaron múltiples factores de corta, mediana y larga duración. Así, se tiene que la marginación en términos productivos de Samaná impidió un proceso de acumulación de capital en igual proporción al que experimentaron otras localidades cafeteras, lo que restringió la reinversión en otras actividades económicas y limitó el desarrollo de un mercado interno sólido que densificara las relaciones comerciales con los centros económicos regionales. Tal marginación se expresó en la pobre infraestructura vial del municipio, su bajo nivel de urbanización y su poca densificación. Por esas características, la crisis y la subsiguiente modificación del modelo productivo cafetero tuvieron un impacto más pronunciado en la localidad. Allí, los pequeños y medianos productores, al no alcanzar los niveles de productividad exigidos y ser afectados por las plagas, vieron reducidos sus ingresos considerablemente, hasta el punto de amenazar la reproducción de su modo de vida. En relación con ese rezago productivo y el aislamiento de los mercados regionales, la presencia del Estado en el municipio era precaria. La FNC, cuyas funciones se limitaban al impulso productivo y a la provisión de algunos bienes y servicios públicos, no fue, como lo dice cierta literatura, el "sustituto del Estado" en la región. El control del territorio rural por parte de la institucionalidad estatal era deficiente, en tanto que no garantizaba el cumplimiento de dos de sus funciones básicas: la provisión de seguridad y la administración de justicia.

Tales condiciones económicas y políticas, al igual que la topografía y ubicación estratégica del municipio, constituyeron el escenario ideal para que las Farc se asentaran a mediados de la década de los noventa. Con sus acciones armadas terminaron por erosionar aún más la institucionalidad del Estado, al punto que buena parte de la ruralidad de Samaná se quedó por varios años sin fuerza pública y sin autoridad a quien los pobladores pudieran acudir. La erosión de la poca institucionalidad existente y la constitución de la guerrilla como el poder fáctico de la región dejaron zonas enteras a disposición de quienes a bien pudieran desarrollar actividades ilícitas.

La difícil situación económica de los campesinos y trabajadores agrícolas agudizada por la crisis cafetera llevó a que muchos de ellos salieran a las ciudades y a otras regiones del país en busca de una mejor fortuna. Algunos se ubicaron en regiones cocaleras donde tuvieron una socialización con el mundo de los cultivos ilícitos. A su regreso a Samaná, 
llevaron consigo el cúmulo de experiencias, conocimientos y entusiasmo acerca de los beneficios de la coca, los cuales trasmitieron a sus coterráneos. En un contexto de precariedad económica y ausencia de regulación estatal esas palabras tuvieron resonancia. Además, para ese entonces las Farc ya se habían establecido en el territorio, por lo que contaban con el grupo capaz de regular la actividad económica ilegal. La guerrilla también se encargó de presionar e incentivar a los caficultores que aún no estaban convencidos para que sembraran coca, algunos aceptaron y cultivaron, otros se rehusaron y tuvieron que abandonar sus tierras.

La presencia del grupo insurgente y la existencia de cultivos de coca atrajeron a los paramilitares, desencadenándose un recrudecimiento de la confrontación armada. A la disputa por el territorio terminó por sumarse la fuerza pública que luego de años volvía a Samaná. La inestabilidad que trajo la guerra se vio reflejada en los robos, saqueos y extorsiones que tuvieron que padecer tanto los caficultores que mantuvieron sus prácticas tradicionales como los que fueron forzados (por la presión de las armas o por la presión del hambre) a trabajar con los cultivos ilícitos.

En términos generales, ese fue el proceso descrito en el artículo. Sin embargo, la historia no terminó aquí. Las consecuencias de casi una década de conflicto armado agravaron la ya bastante complicada situación de los cafeteros en varios sentidos. Primero, por los fuertes enfrentamientos entre las Farc y los paramilitares, muchos de ellos tuvieron que dejar- temporal o definitivamente- sus tierras. Como es obvio, para un campesino que deja por varios días su tierra las consecuencias son desastrosas: los animales se mueren, las cosechas se pierden $y$, en este caso, los bienes ${ }^{37}$ son robados. Los que se van y nunca regresan, como es sabido, pasan a engrosar las filas del sector informal de la economía en las ciudades. Segundo, respecto a la producción del café, la guerra llevó a un abandono masivo del campo por parte de los jóvenes, quienes por temor a ser reclutados se desplazaron a otros lugares. Esto, sumado al jornal más caro que se le pagaba a los que trabajaban con coca, llevó a un declive de la mano de obra para las labores agrícolas. Tercero, relacionado con lo anterior, la salida en masa de los jóvenes del sector rural de Samaná generó una transformación en la familia y sociedad campesina hasta el punto que, como reconocen los mismos caficultores, en las veredas sólo quedan los más viejos. Este problema, más allá de los aspectos productivos, genera serias dificultades cuando se piensa en la reproducción de un modo de vida. Por las razones mencionadas y por todas las que se han quedado por fuera, es que los cafeteros de Samaná tienen razón cuando dicen que la violencia fue otra de las plagas que les cayó.

\footnotetext{
${ }^{37}$ Como se mencionó en el texto, toda clase de bienes: alimentos, animales, cables de luz, paredes, armas, etc.
} 
Crisis cafetera, conflicto armado y cultivos ilícitos en el oriente caldense: el caso de Samaná |

\section{ANEXOS}

GRÁFICA 1: Intensidad de la confrontación armada.
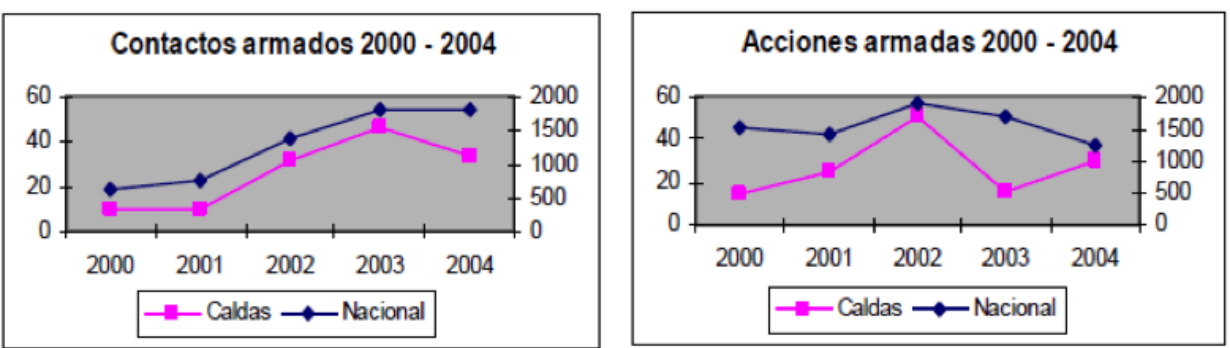

Fuente: Observatorio del Programa Presidencial de DH y DIH (2005).

TABLA1: Número de trilladoras en Caldas según municipio entre 1926 y 1971.

\begin{tabular}{|c|c|c|c|c|c|c|}
\hline \multirow{2}{*}{ Municipio } & \multicolumn{6}{|c|}{ Número } \\
\hline & 1924 & 1939 & 1941 & 1942 & 1947 & 1971 \\
\hline Manizales & 5 & 4 & 4 & 3 & 4 & 4 \\
\hline Armenia & 5 & 7 & 8 & 7 & 8 & 10 \\
\hline Pereira & 7 & 7 & 5 & 5 & 5 & 9 \\
\hline Aguadas & 2 & 2 & 2 & & 1 & \\
\hline Anserma & 1 & 1 & 1 & 1 & 1 & \\
\hline Apía & 1 & & & & & \\
\hline Aranzazu & 1 & & 1 & & & \\
\hline Belalcázar & 3 & 3 & & & 2 & \\
\hline Belén de U. & 2 & 2 & & & 1 & \\
\hline Calarcá & 2 & & 1 & 1 & 1 & \\
\hline Chinchiná & 2 & 3 & 1 & 1 & 1 & \\
\hline Filandia & 1 & & & & & \\
\hline La Virginia & & & & 1 & & 1 \\
\hline Manzanares & 2 & & 2 & & 2 & \\
\hline Marsella & 1 & & & & & \\
\hline Montenegro & 2 & & & & & \\
\hline Neira & 3 & 1 & 1 & 1 & 1 & \\
\hline Pácora & 1 & 2 & 2 & & 3 & \\
\hline Palestina & 2 & & & & & \\
\hline Pensilvania & 2 & & & & & \\
\hline Quimbaya & 2 & & & & & \\
\hline Riosucio & 1 & 2 & 2 & 1 & & \\
\hline Risaralda & 1 & & & & & \\
\hline Salamina & 1 & & & & & \\
\hline Samaná & 1 & & & & & \\
\hline Santa Rosa & 3 & 2 & 5 & 5 & 5 & 4 \\
\hline Total & 54 & 36 & 35 & 27 & 34 & 28 \\
\hline
\end{tabular}

Fuente: Vallecilla, 2002, p. 208. 
TABLA 2: Trilladoras de café y capacidad diaria de trilla en el Antiguo Caldas.

\begin{tabular}{|l|l|l|l|l|l|l|l|l|}
\hline \multirow{2}{*}{ Municipio } & \multicolumn{2}{|c|}{$1924-1927$} & \multicolumn{4}{c|}{1941} & \multicolumn{3}{c|}{1945} \\
\cline { 2 - 9 } & No. & Capacidad & No. & Capacidad & $\begin{array}{c}\% \\
\text { capacidad }\end{array}$ & No. & Capacidad & $\begin{array}{c}\% \\
\text { Capacidad }\end{array}$ \\
\hline Total & 54 & n.a & 35 & 64950 & 100 & 28 & 60000 & 100 \\
\hline Manizales & 4 & 2750 & 4 & 7400 & 11.4 & 4 & 20300 & 15.5 \\
\hline Armenia & 5 & n.d & 8 & 28950 & 44.6 & 7 & 22680 & 37.8 \\
\hline Pereira & 8 & 9000 & 5 & 12500 & 19.2 & 6 & 13200 & 22 \\
\hline Resto & 37 & n.d & 18 & 16100 & 24.8 & 11 & 14820 & 24.7 \\
\hline
\end{tabular}

Fuente: Vallecilla, 2002, p. 211.

MAPA 1: Subregiones del departamento de Caldas

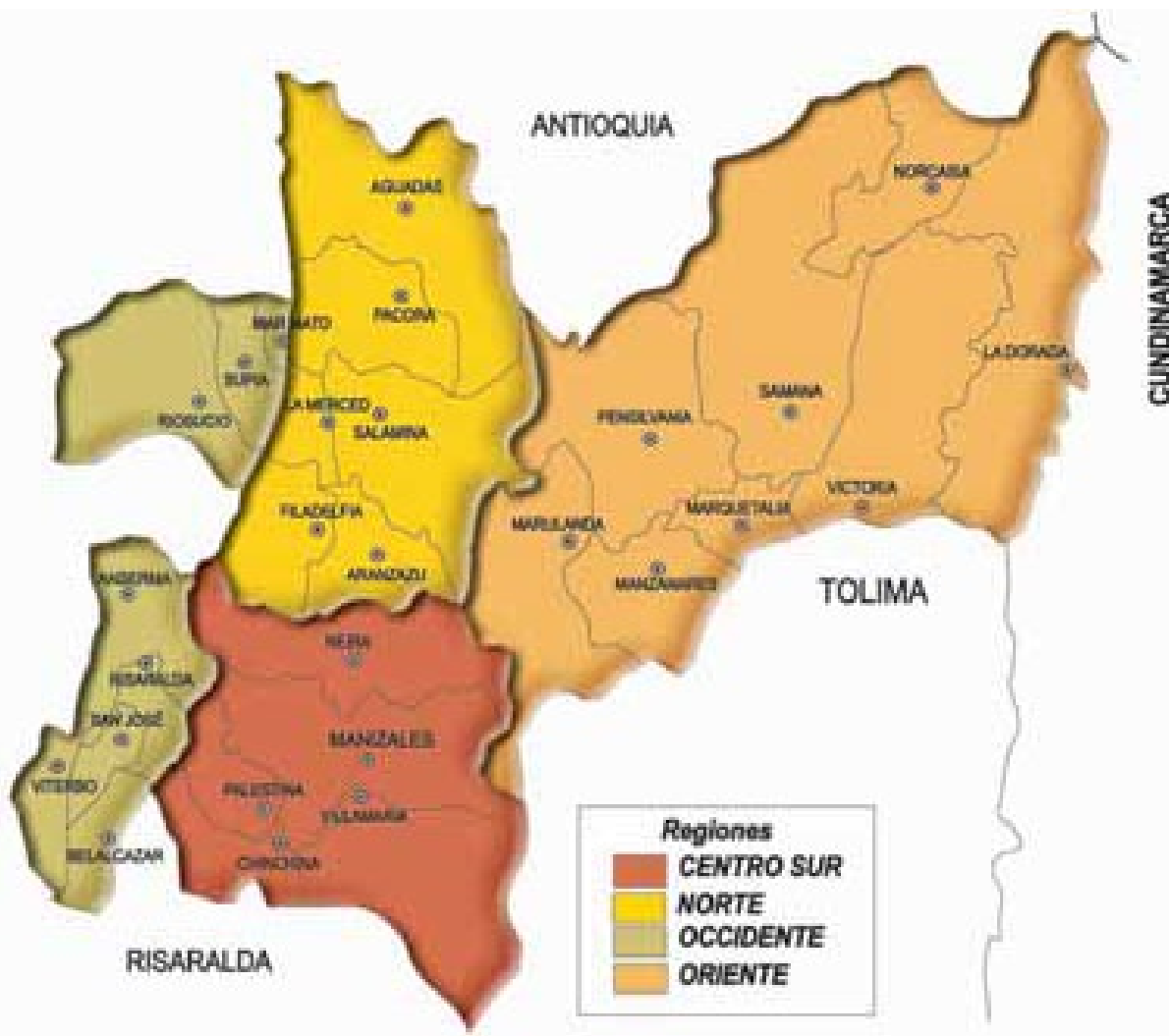

Fuente: Observatorio del Programa Presidencial de DH y DIH (2005).

80 | antropol.sociol. Vol. 18 No. 1, enero - junio 2016, págs. 47-85 | 
Crisis cafetera, conflicto armado y cultivos ilícitos en el oriente caldense: el caso de Samaná |

MAPA 2: Mapa físico de Caldas

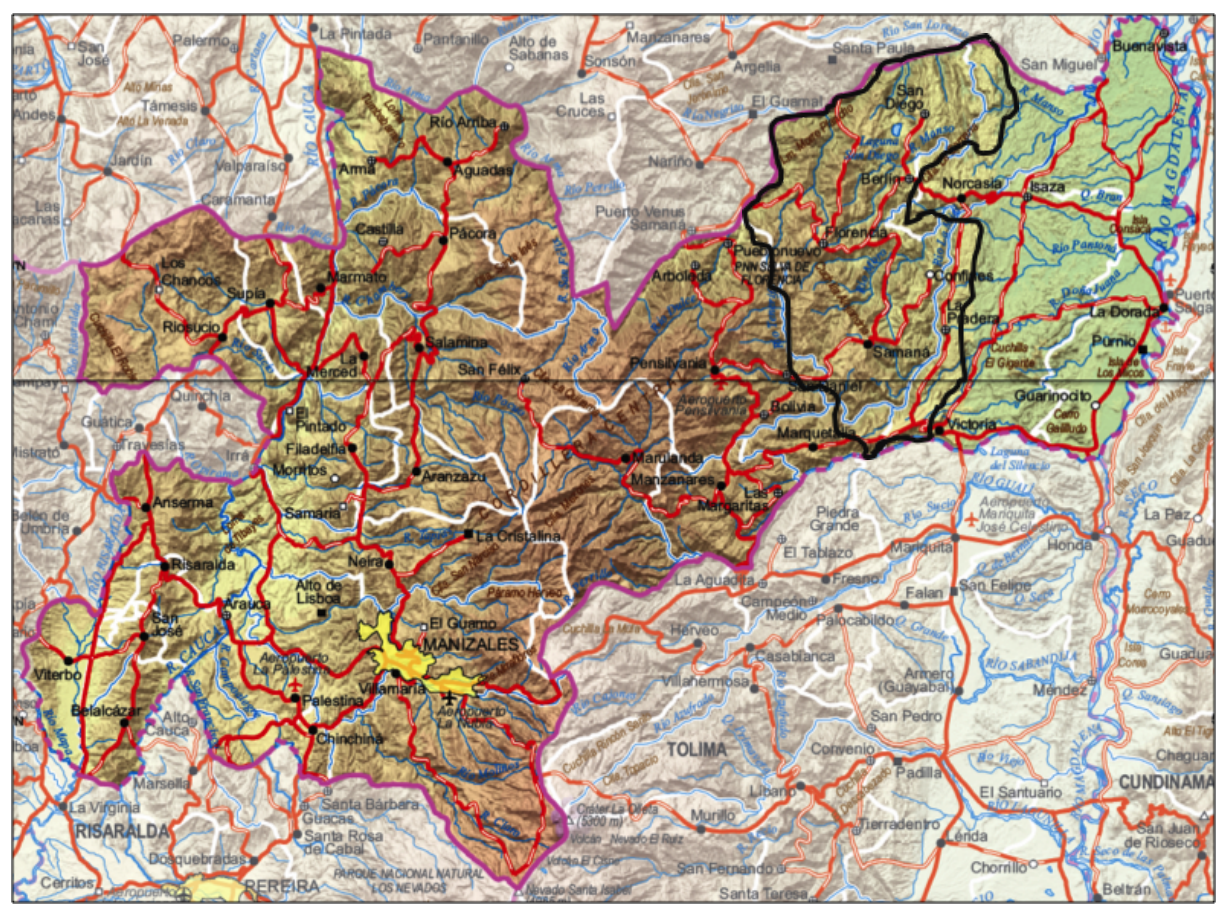

Resaltado en negro el municipio de Samaná. Fuente: IGAC

TABLA 3: Censo de establecimientos comerciales hasta 1980.

\begin{tabular}{|l|c|}
\hline \multicolumn{1}{|c|}{ Establecimiento comercial } & Número \\
\hline Almacenes de mercancías & 25 \\
\hline Abarrotes & 30 \\
\hline Restaurantes y cafeterías & 22 \\
\hline Cantinas & 47 \\
\hline Hospedajes & 10 \\
\hline Panaderías & 5 \\
\hline Fruterías & 1 \\
\hline Farmacias & 4 \\
\hline Discotecas & 5 \\
\hline Sastrerías & 5 \\
\hline Talleres de mecánica & 3 \\
\hline Bombas de gasolina & 2 \\
\hline Otras & 10 \\
\hline
\end{tabular}

Fuente: Loaiza, 1984. Citado en: Leguizamo, 2011. 
MAPA 3: Presencia de las Farc, el Epl y los paramilitares en Caldas

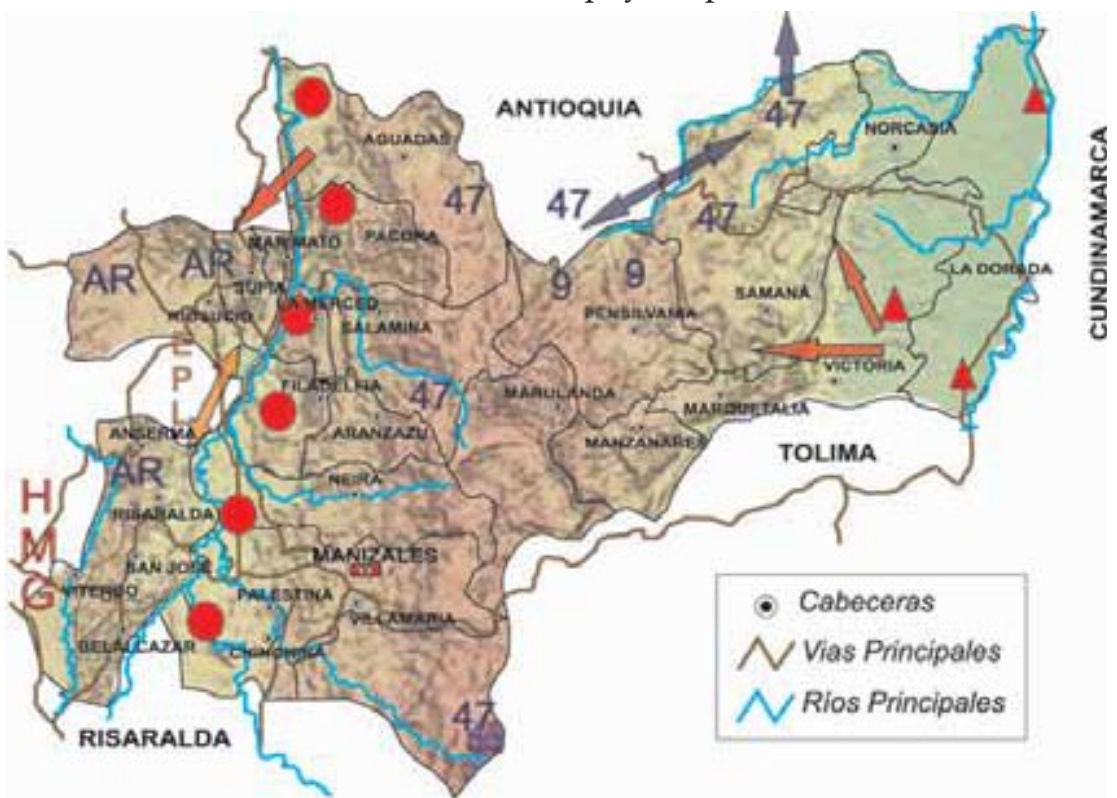

AUTODEFENSAS

Frente Cacique Pipintá, del BCB

A Autodefensas Campesinas del Magdalena Medio

- Autodefensas Urbanas

HMG: Hẻroes y Märtires de Guática del BCB

\section{FARC}

Frentes: $9-47$

AR Aurelio Rodriguez

EPL

EPL Ejército Popular de Liberación

Fuente: Observatorio del Programa Presidencial de DH y DIH (2005) 


\section{FRAGMENTO DE ENTREVISTA:}

\section{Gremio, políticos y provisión de bienes públicos}

“Ese es el orgullo que tengo, que logré electrificar esta vereda y logré sacar este ramal de carretera. Con el comité (...) porque cuando eso yo también me metía en la política, y entonces me valí de un señor, Renán Barco, de Dorada, él manejaba la maquinaria del departamento. Le dije yo: 'nosotros estamos incomunicados allá, esa es la despensa del pueblo'. Dijo '¿y qué es lo que quiere?' -'Que usted me haga el favor y me colabore (...) me eche siquiera un kilómetro, y luego yo, como estoy en el comité y usted es amigo de los del comité, entremos esos ramales (vías) por la Federación. Dijo ‘Listo, hágale (...) y usted como es representante allá del Comité Municipal de Samaná, cuando vayan y se reúnan en Manizales briegue que todos los compañeros aprueben que ese ramal para allá quede por la Federación Nacional de Cafeteros' (...) Yo tenía un amigo en Pensilvania (...) que era presidente del Comité Departamental (...) Le dije ' Doctor, nosotros queremos que metan un ramal por allá', respondió 'Mañana, cuando estemos allá en la plenaria usted va a exponer eso, y si los otros aprueban, los de Marquetalia, Pensilvania y Manzanares, haga de cuenta que es un hecho'. Preciso, ya nos habíamos cuadrado. Yo les dije: 'Si ustedes quieren que nosotros les apoyemos algo, alguna petición que ustedes hagan (...) Eso fue como un tiro, ya lo agarró el Comité de cafeteros y lo sacó (...)."

\section{FRAGMENTO DE ENTREVISTA 2:}

Los tratos diferentes de los actores armados

(...) “La guerrilla yo no sé si era ladrona o no porque aquí llegaban y decían 'Necesitamos cuatro gallinas' y ahí mismo las pagaban' (...) Allí había una señora que vendía pollos y le decían, inclusive cuando estaban combatiendo con los paras,' véndanos cinco pollos gordos, no tenemos plata, después los pagamos' y a los ocho, quince días '¿cuánto le debemos señora?' y tenga. A nosotros pa' que, hay que decir la verdad que la guerrilla no nos robó nada. (...) "Aquí los primeros que vinieron fueros los paracos y dijeron '¿Aquí estuvo la guerrilla?' Le dije 'Sí señor, aquí estuvo' - ¿Comieron aquí?' 'Sí, comieron. Tocó darles de comer' le dije yo. - ¿¿Pagaron?' Le dije 'sí, sí pagaron'. Después llegó el ejército y preguntaron ‘Aquí estuvo la guerrilla?" les dije 'sí'. - ¿'Les daban de comer?' -'Sí, aquí compraban que comer'. - '¿Pagaron?' -'Sí, sí pagaron' - ¿Los paracos también estuvieron?' -'Sí' - ¿Les dieron de comer?' - 'Sí, les dimos de comer.' - ‘Pagaron?' -'No, no pagaron'. Los paracos a veces traían y le obligaban a uno a hacerles la comida. Eso llegaban y decían 'necesitamos diez almuerzos' y listo (...) 
[Habla la esposa de Don Gamaliel] Llegaban y decían que les hiciera 5 libras de arroz. Y yo con esa rabia, prendiéndole candela al fogón porque no había gas. $\mathrm{Y}$ entonces le eche unas buenas cucharadas de sal y me dijo un paraco de esos '¿Eso no será mucha sal?' y yo le respondí 'esto no es pa' mí'... uno ya cansado (...) Le dije yo al ejército 'Qué hace pues uno si el que tiene las armas manda'”' (Entrevista a Don Gamaliel y su esposa realizada en 2014).

\section{Referencias Bibliográficas}

Alzate, M.. (2001). Historia del municipio de Samaná. Manizales: Talleres Litográficos Asociados. Arango, M.. (1977). Café e industria 1850-1930. Bogotá: Carlos Valencia.

Bolívar, I., González, F.y Vásquez, T. (2002). Violencia política en Colombia. Bogotá: CINEP.

CERAC. (2014). Tipología de los municipios de Colombia según el conflicto armado interno entre 2000 y 2012. Colombia: CERAC. Recuperado de: https://docs.google.com/spreadsheets/ d/1ITvbEU79Ok_GhaDmN12mCeHBFfBzoa4GfNT68wyAnXo/edit\#gid=1514359174

Comisión de Ajuste de la Institucionalidad Cafetera. (2002). El Café, Capital Social Estratégico. Bogotá: Ministerio de Hacienda.

Corporación Autónoma Regional de Caldas (2007). Plan de Gestión Ambiental. Manizales: CORPOCALDAS.

Cubides Cipagauta, F. (1998). La violencia y el municipio colombiano 1980-1997. Bogotá: Universidad Nacional de Colombia.

Currie, L. (1952). Caldas en 1952. Programa económico y administrativo para el Departamento de Caldas. Manizales: Imprenta Departamental.

Defensoría del Pueblo (2003). Resolución Defensorial Nacional No. 028. "La crisis cafetera y las fumigaciones en el Departamento de Caldas". Manizales. Recuperado de: www.defensoria. gov.co/attachment/206/defensorial28.pdf

Dube, O. y Vargas, J. (2006). Resource curse in reverse: the coffee crisis and armed conflict in Colombia. Bogotá: Universidad de los Andes, publicación electrónica.

Echandía, C. (2006). Dos décadas del escalamiento del conflicto armado en Colombia. Bogotá: Universidad del Externado.

Franco, M. (2006). Institucionalidad, capital social y violencia. Bogotá: Universidad de los Andes.

García, A. (1978). Geografía económica de Caldas. Bogotá: Banco de la República, Archivo de Economía Nacional.

García Villegas, M. y Espinosa, J. (2013). El derecho al Estado. Bogotá: Ediciones Antropos.

Giraldo, L. (2001). Modernización e industrialización en el Antiguo Caldas. Manizales: Universidad de Caldas.

Gutiérrez Sanín, F. (2004). Criminales y rebeldes: una discusión de la economía política del conflicto armado desde el caso colombiano. Estudios Políticos (24), 37-71.

Leguizamo, A. (2011). Territorio, trabajo y conflicto armado. (Tesis inédita de pregrado). Universidad de Caldas, Manizales.

Loaiza, J. (1984). Monografía de Samaná. Manizales: Imprenta Departamental.

Machado, A. (1988). El café de la aparcería al capitalismo. Bogotá: Tercer Mundo Editores.

Monsalve, D. (1927). Colombia cafetera. Barcelona: Artes Gráficas.

Observatorio del Programa Presidencial de DH y DIH (2004) Algunos indicadores sobre la situación de derechos humanos en la región del Eje Cafetero. Bogotá: Vicepresidencia de la 
República, Observatorio del Programa Presidencial de DH y DIH.

(2005). Dinámica reciente de la confrontación armada en Caldas. Bogotá:

Vicepresidencia de la República, Observatorio del Programa Presidencial de DH y DIH.

Palacios, M. (1983). El café en Colombia, 1850-1970. Una historia económica, social y política.

Bogotá: El Áncora Editores.

PNUD (2004). Informe Regional de Desarrollo Humano 2004. Un pacto por la región. Manizales: PNUD.

Rincón, J. J. (2006). Trabajo, territorio y política expresiones de la crisis cafetera. Medellín: La carreta editores.

Robledo, J. (1998). El café en Colombia. Un análisis independiente. Bogotá: El Áncora Editores.

Rodríguez, M.(1993). El empresario industrial del Viejo Caldas. Colombia: Universidad de los Andes.

Sánchez, G. (Coordinador). (1999). Conflictos regionales. La crisis del Eje Cafetero. Bogotá: Fescol, IEPRI.

Vallecilla, J. (2002). La economía cafetera y el desarrollo regional. Manizales: Universidad de Caldas.

Prensa y portales web:

El Tiempo. “Los Medina. Historia de un exterminio". Publicado el 17/08/93.

"Asesinado ex alcalde de Samaná, Caldas". Publicado el 24/02/1997.

"Mujer murió en iglesia atacada por las Farc en Florencia" Publicado el 24/02/1997.

"Viviendo en la zozobra". Publicado el 06/08/2000.

La Patria. "Nos cansamos de sufrir y por eso nos desmovilizamos". Publicado el 31/01/2008.

"Línea de tiempo Registros del terror de las Farc en Caldas. 01/06 2014

“El cura Reinoso, ahora investigado por homicidio". Publicado el 13/10/2014.

www.verdadabierta.com. "Karina', a responder por 143 crímenes en Caldas y Antioquia". Publicado el 24/01/ 2014.

"Las Farc cosecharon odios en el oriente antioqueño". Publicado el

$08 / 02 / 2014$.

“La ilusión de volver a El Congal”. Publicado el 22/02/2014.

“Todos mataron a Samaná". Publicado el 26/02/2014.

“Minas antipersonal, 'enemigas' de la restitución en el oriente de

Caldas". Publicado el 01/09/2014.

\section{Entrevistas:}

Entrevista a Don Víctor, caficultor de Samaná (2014)

Entrevista a Don Arley, caficultor de Samaná y representante del Comité de Cafeteros del Oriente de Caldas (2014)

Entrevista a Don Gamaliel, caficultor de Samaná y líder comunitario (Octubre de 2014)

Entrevista a Doña Dora, caficultora de Samaná (2014)

Entrevista a los "hermanos Pellejo", caficultores de Samaná (2014)

Entrevista a Jaime, funcionario de Corpocaldas seccional Samaná (2014) 